\title{
Dynamic housing expenditures and household welfare
}

\author{
Laura Blow \\ Lars Nesheim
}

The Institute for Fiscal Studies

Department of Economics, UCL

cemmap working paper CWP04/09 


\title{
Dynamic housing expenditures and household welfare
}

\author{
Lars Nesheim Laura Blow \\ CEMMAP IFS \\ UCL, and IFS
}

January 2009 


\begin{abstract}
In this paper we develop a measure of current "expenditures" on housing services for owner-occupiers. Having such a measure is important for measuring the relative welfare of households, especially when comparing renters and owners and for measuring inflation. From a theoretical perspective expenditures equal the "shadow price" of housing services (the marginal rate of substitution between housing services and non-durable consumption) multiplied by the quantity of housing services consumed. In an idealised world, two simple measures of the shadow price are available; the user cost of housing capital and the rental price of an equivalent rental house. However, imperfect capital markets, risk aversion, the tax system, moving costs and systematic differences between houses available in the rental and owner-occupied sectors drive a wedge between the shadow price of housing and these other two measures. This paper contributes to previous research by calibrating a lifecycle model of housing investment and consumption to data from the UK Family Expenditure Survey and by developing measures of the shadow price of housing that take into account uncertainty in house prices, interest rates and incomes, dynamic life cycle choices, and liquidity constraints taht depend on both income and house value.
\end{abstract}

JEL: C88, D12 ,E21, R21

Keywords: shadow price, housing, liquidity constraints, lifeycle models

Correspondence: 1 .nesheim@ucl.ac.uk

Correspondence: 1.blow@ifs.org.uk

Acknowledgements: Financial support from the ESRC through grant number RES-000-23-1448 and through the ESRC Centre for Microdata Methods and Practice (CEMMAP) (ESRC grant number RES-589-28-0001) is gratefully acknowledged. All errors remain the responsibility of the authors. 


\section{Introduction}

Housing is extremely important both as a consumption good and as an asset. It is the most important asset for a large majority of households (other than human capital and pension wealth). In 2002, $70 \%$ of British households in the Expenditure and Food Survey (EFS) sample owned their house. In 2000, housing wealth made up $80 \%$ of the non-pension wealth of households in the British Household Panel Survey (BHPS) sample. The housing stock also represents a large component of the national capital stock, accounting for $57 \%$ of the total value of the UK net capital stock at the end of $2003^{1}$.

As a consumption good, housing is also very important. For renters in the private rental sector, housing expenditures averaged $33 \%$ percent of the household budget in the 2002 FES sample. For renters in the social housing sector, these expenditures averaged $15 \%$ percent of the household budget $^{2}$. For homeowners with mortgages outstanding, direct housing expenditures (mortgage payments, DIY expenditures, repairs and insurance) averaged $25 \%$ percent in the 2002 FES sample. For homeowners with no mortgage outstanding, the equivalent figure was $13 \%$. These spending measures, however, are not proper measures of housing consumption for homeowners, since they conflate housing investment and housing consumption and neglect the opportunity cost of equity invested.

This last point raises a crucial issue. For owner-occupiers, how should current "expenditures" on housing services be measured? From a theoretical welfare economics perspective, the answer is clear. Expenditures equal the "shadow price" of housing services (the marginal rate of substitution between housing services and non-durable consumption) multiplied by the quantity of housing services consumed. In an idealised world, two simple measures of the shadow price are available. One is the user cost of housing capital. The other is the rental price of an equivalent rental house. However, imperfect capital markets, risk aversion, the tax system and moving costs drive a wedge between the shadow price of housing and the user cost of housing. These factors and systematic differences between houses available in the rental and owner-occupied sectors, drive a wedge between rents and the shadow price. Rental equivalence is particularly untenable in the UK. Quality differences

\footnotetext{
${ }^{1}$ Office for National Statistics http://www.statistics.gov.uk/cci/nugget.asp?id=479

${ }^{2}$ Housing benefit is a non-cash benefit for these households and is therefore not treated as discretionary expenditure. If imputed housing benefit is added to expenditure then the budget share of housing for social renters becomes $34 \%$.
} 
between rental and owner occupied housing are stark. The private rental market makes up only $8.5 \%$ of the entire housing market and the overlap is small. The rest of the rental market, $24 \%$ of the housing market as a whole, is made up of social housing. Thus, in real world housing markets, neither of the commonly used methods provide valid estimates of the shadow price of housing and expenditures on housing services by owner-occupiers.

Measuring the shadow price of housing correctly requires an understanding of consumer demand for housing as an asset and as a consumption good, but, despite its importance, research in this area has been limited by computational and data problems. Until recently, the role of housing as an asset has only been studied in very simple models with two periods, in models with limited uncertainty, or in models with simple closed form solutions (Poterba (1992), Nordvik (2001), Ortalo-Magne and Rady (2002)). Empirical work has focused on testing some implications of housing models and impacts of housing price shocks and volatility without studying the full properties of lifecycle housing demand models (Muellbauer and Murphy (1997), Campbell and Cocco (2003), Attanasio, Blow, Hamilton, and Leicester (2004), Banks et al. (2004), Disney et al. (2004)). More recent theoretical work has begun to address these issues in realistic lifecycle models of housing demand (Campbell and Cocco (2007), Li and Yao (2007), and Díaz and Luengo-Prado (2007)). Yet, this work has only begun and the interaction of housing demand with consumption, savings, and insurance is only little understood.

This paper contributes to this line of research by calibrating a lifecycle model of housing investment and consumption to data from the Family Expenditure Survey (FES) and by developing measures of the shadow price of housing that take into account uncertainty in house prices, interest rates and incomes, dynamic life cycle choices, and liquidity constraints that depend on both income and house value. Previous research has ignored variability in interest rates and has ignored the income related liquidity constraint. Our research makes use of sophisticated computational methods for approximation, numerical integration, and dynamic programming using splines in four dimensions to approximate the optimal value function of households. We use these methods and the data described above to analyse how the shadow price of housing services depends not only on current housing market conditions and household demographics but also on the levels and volatility of future prices, interest rates, borrowing constraints, and income.

Developing a good measure of homeowners' expenditures on housing services is crucial for many welfare and policy questions. It is important for mea- 
suring the relative welfare of households, especially when comparing renters and owners. It is also important for analysing consumer expenditure on other goods. Nondurable consumption expenditures are not independent of housing expenditures. For example, expenditures on services such as heating and electricity are most obviously interrelated with the quantity of housing services consumed. Failure to take these relationships into account can lead to misinterpretations of data on nondurable consumption expenditures.

Proper measurements of expenditures on housing services are also essential for measuring inflation. In the UK, the RPI includes an estimate of average mortgage interest payments plus an estimated house depreciation component as a measure of housing costs for owner occupiers, whereas the US CPI uses the rent for an equivalent rental property. These methods are adequate for many purposes and give useful and timely results without having to fully model the consumer's dynamic problem. But they are severely flawed as measures of housing expenditure. The former does not equal the shadow price of housing except in very special circumstances. The latter is plagued with error when, as is the case in the UK, it is difficult to identify an equivalent rental property. To properly measure the cost of living or of purchasing a fixed basket of goods and services, one needs to use the shadow price of housing services.

In this paper, we use data from the FES to calibrate a computational lifecycle model of the demand for housing and non-durable consumption with uncertain housing prices, interest rates, and income and with liquidity constraints. We compute shadow prices of housing for different demographic groups distinguished by age, income, family structure, and education, using the FES data. Finally we use the computed shadow prices to calculate measures of housing expenditure for owner occupiers in different demographic groups.

\section{Model}

A household has initial total wealth $w_{t}$. The size of the household at time $t$ is $n_{t}$. We assume $n_{t}$ evolves deterministically. The household faces exogenous stochastic price processes $q_{t}=\left(p_{t}, r_{t}, y_{t}\right)$ for all $t=1, \ldots, T+1$ where $p_{t}$ is the housing price, $y_{t}$ is the labour income price, and $r_{t}$ is the gross interest rate earned on bank savings. Given these exogenous factors, the household chooses non-durable consumption $c_{t}$, housing quantity $h_{t}$, and bank savings 
$s_{t}$ for $t=1, \ldots, T$ to maximise utility. The household is liquidity constrained in that

$$
\begin{aligned}
& s_{t} \geq-b_{y 0}-b_{y 1} y_{t} \\
& s_{t} \geq-b_{h 0}-b_{h 1} p_{t} h_{t}
\end{aligned}
$$

and $w_{t} \geq w_{t}^{L} \cdot{ }^{3}$ Define $v\left(w_{t}, q_{t}, t\right)$ as the value of the maximised utility. at period $t$ given realised values of the state variables $\left(w_{t}, q_{t}\right)$. This function satisfies

$$
\begin{aligned}
& v\left(w_{t}, q_{t}, t\right)= \\
& \max _{\left\{s_{t}, c_{t}, h_{t}\right\}}\left\{u\left(c_{t}, h_{t}, n_{t}\right)+\beta \int v\left(w_{t+1}, q_{t+1}, t+1\right) f\left(q_{t+1}\left|q_{t}\right|\right) d q_{t+1}\right\}
\end{aligned}
$$

subject to

$$
\left\{\begin{array}{c}
c_{t}+s_{t}+p_{t} h_{t}=w_{t} \\
w_{t+1}=r_{t+1} s_{t}+y_{t+1}+p_{t+1} h_{t} \\
s_{t} \geq-b_{y 0}-b_{y 1} y_{t} \\
s_{t} \geq-b_{h 0}-b_{h 1} p_{t} h_{t} \\
r_{t+1}^{H} s_{t}+y_{t+1}^{L}+p_{t+1}^{L} h_{t} \geq w_{t+1}^{L} \\
c_{t}, h_{t} \geq 0
\end{array}\right\} .
$$

The first constraint is the "within-period" budget constraint. Within a period, total expenditure on consumption, savings and housing must equal total resources. The second is the investment return equation. Period $t+1$ assets equal savings multiplied by gross interest plus income plus the value of the house. The final inequality constraint is the "no bankruptcy" constraint. This constraint changes over time and requires that the value of total wealth be large enough to finance a minimum consumption level even in the worst of all possible worlds.

We assume that

$$
u\left(c_{t}, h_{t}, n_{t}\right)=\frac{n_{t}^{-\sigma}\left(c_{t}^{\alpha} h_{t}^{1-\alpha}\right)^{\sigma_{t}}}{\sigma_{t}}
$$

and

$$
v\left(w_{T+1}, q_{T+1}, T+1\right)=\frac{w_{T+1}^{\sigma_{T+1}}}{\sigma_{T+1}} .
$$

\footnotetext{
${ }^{3}$ This last constraint is a feasibility constraint. In theory, because we assume $\lim _{c \rightarrow 0} \frac{\partial u(c, h)}{\partial c}=\infty$. In practice, it sometimes binds due to numerical approximation errors.
} 


\subsection{Prices}

Previous authors have allowed for stochastic real house prices and incomes but not for stochastic real interest rates. However, Figures 1 and 2 below show that both real house prices and real interest rates are stochastic. We model the joint evolution of house prices, interest rates and incomes as an $\operatorname{VAR}(1)$ with drift after a suitable transformation. Let $z_{t} \in R_{3}$ and let $z_{t}=A_{t}+\Gamma z_{t-1}+\varepsilon_{t}$ where $\varepsilon_{t} \sim N\left(\mu_{\varepsilon}, \Sigma_{\varepsilon}\right)$. We define

$$
p_{t}=p^{H}\left(\frac{p^{L}+\exp \left(z_{t}^{1}\right)}{p^{H}+\exp \left(z_{t}^{1}\right)}\right)
$$

so that

$$
z_{t}^{1}=\ln \left(\frac{p_{t}-p^{L}}{p^{H}-p_{t}}\right)+\ln p^{H} .
$$

While $z_{t}$ is an $\operatorname{AR}(1)$ process, the price is constrained to a compact set. Similarly,

$$
\begin{aligned}
& r_{t}=r^{H}\left(\frac{r^{L}+\exp \left(z_{t}^{2}\right)}{r^{H}+\exp \left(z_{t}^{2}\right)}\right) \\
& y_{t}=y^{H}\left(\frac{y^{L}+\exp \left(z_{t}^{3}\right)}{y^{H}+\exp \left(z_{t}^{3}\right)}\right) .
\end{aligned}
$$

In summary the vector $z_{t}$ follows a $\operatorname{VAR}(1)$. The prices in the economy, $\left(p_{t}, r_{t}, y_{t}\right)$ are nonlinear transformations of $z_{t}$. This transformation has the advantages that 1$)\left(p_{t}, r_{t}, y_{t}\right)$ lie in a compact set if the minimum and maximum prices are finite and 2) the transformation nests the log transformation as a special case $\left(p_{L}=r_{L}=y_{L}=0\right.$ and $\left.p_{H}=r_{H}=y_{H}=\infty\right)$. That is, in this latter special case $\left(\ln p_{t}, \ln r_{t}, \ln y_{t}\right)=z_{t}$ follows an $\operatorname{VAR}(1)$. We estimate the parameters of the process $z_{t}=A_{t}+\Gamma z_{t-1}+\varepsilon_{t}$ using FES data as described in Section 3.5.

\section{Baseline calibration}

We first calibrate the model using data from the UK economy and parameter values taken from the literature. 


\subsection{Preference parameters}

The three utility parameters in the model are $\alpha$, the consumption share of expenditure in the within period utility function, $\sigma_{u}$, one minus the coefficient of relative risk aversion, and $\beta$, the discount factor. We use $\alpha=0.8$ as a baseline figure for the housing share of the within period budget. Li and Yao (2007) use $\alpha=0.8$ for their model of the US economy. For the coefficient

of relative risk aversion, we follow $\mathrm{Li}$ and Yao (2007), Campbell and Cocco (2007), and Díaz and Luengo-Prado (2007) and use $\sigma=-1$ (i.e. $1-\sigma=2$ ). For the discount factor, we follow Campbell and Cocco (2007) and use $\beta=$ 0.98 . We set the marginal value of bequests equal to 0.6 .

\subsection{Demographics}

Households begin life at age 20 and live until 82. Each period in the model represents one year. We simulated the model once for each education group $e \in\{0,1\}$ and for each cohort $c=\{1900,1910, \ldots, 1980\}$. In the model, we assume that the household size of each cohort group follows a deterministic lifecycle path. For each group, we estimate the lifecycle path of household size as follows.

Using the FES, for each education group, we predict the number of adults per household using the regression equation

$$
\ln n_{1}=\sum_{i=1}^{2} \sum_{j=1}^{2} \gamma_{i j} t^{i} y^{i}+\varepsilon
$$

where $t$ is the age of the head of household and $y$ is the year of birth. For each cohort and education group, we then compute the group average of $n_{1}$. The number of children per household is predicted from a multinomial logit in which the utility of having $k$ children is

$$
v_{k}=\sum_{i=1}^{2} \sum_{j=1}^{2} \delta_{i j}^{k} t^{i} y^{i}+\varepsilon_{k}
$$

for $k=0, \ldots, 9$. Then, for each cohort and for each education group household size at age $t$ is calculated as

$$
n_{t}=\bar{n}_{1 t}+0.5 \bar{n}_{2 t}
$$


where $\bar{n}_{1 t}$ is the average predicted number of adults in the cohort at age $t$ and $\bar{n}_{2 t}$ is the average predicted number of children.

The time profiles of predicted household size are displayed in Figures 5 8. The profiles are hump shaped, peak in middle age, and mostly range from 1 to 3 . Moreover, the older cohorts have larger household sizes. All profiles appear reasonable except possibly for the 1900 and 1910 cohorts with low education and age less than 60 . Both cohorts have large predicted household sizes at young ages and a big hump at age 50. The sizes predicted for young ages are pure extrapolations to regions outside the support of the data. The humps at age 50 partly represent a post-war baby boom but also are based on limited data and are not reliable. However, the simulations do not use these age ranges for these cohorts so these values have no impact on the results.

\subsection{Liquidity constraints}

Campbell and Cocco (2007) and Díaz and Luengo-Prado (2007) impose a down-payment constraint. Li and Yao (2007) require mortgages to be repaid according to a fixed schedule unless the household remortgages. Neither studies the impact of the additional constraint that borrowing is limited by household income.

In the UK mortgage market, lenders set limits on borrowing based on both income and house value. However, many lenders set different limits depending on the interest rate charged. Moreover, the limits vary across mortgage lenders. Especially in the 1990's and after 2000, a borrower who was unable to secure a sufficiently large mortgage from one lender, could often find another lender who would lend more at a higher rate of interest.

Tables A.3 and A.4 provide some evidence from the Survey of Mortgage Lenders on the ratios of mortgage advance to income and to house value for 1990 to 2001 . During this period, $75 \%$ of mortgage advances were less than about 2.75 times total income and $90 \%$ were less than about 3.10 times total income. At the same time, $75 \%$ of mortgage advances were less than 0.95 times house value and $90 \%$ were less than 0.965 times house value. The tables show that the precise quantiles vary across years. They also show that some borrowers borrow up to (even more than) 3.5 times income and that some borrow more than the value of their house. As a baseline, scenario we simulate the model with $b_{y 0}=0, b_{y 1}=3.5$ and $b_{h 0}=0.1, b_{h 1}=0.8$. Households may borrow at most 3.5 times income and 0.8 times the house value. The parameter $b_{h 0}=0.1$ allows for a small amount of unsecured debt 
such as credit card debt.

\subsection{Initial wealth}

The FES does not contain information on household wealth. For each cohort, we calibrate 1992 wealth so that the average house value predicted by the model for 1992 to 1999 equals the average house value from the FES for the cohort for the same period. For 1992-1999 the FES contains information about the purchase price of the house purchased so that we can compute the average house value. Detailed values are displayed in Table A.5

\subsection{Price processes}

We want to estimate a time series process for $q_{t}=\left(p_{t}, r_{t}, y_{t}\right)$ as an input for the model. To maintain computational tractability and impose structure on the data and the model we assume that these random variables have compact support. Let $q_{t}^{i} \in\left[q_{t}^{i L}, q_{t}^{i H}\right]$. Then define

$$
z_{t}^{i}=\ln \left(\frac{q_{t}^{i}-q^{i L}}{q^{i H}-q_{t}^{i}}\right)+\ln q^{i H}
$$

for $i \in\{1,2,3\}$. e.g.

$$
z_{t}^{1}=\ln \left(\frac{p_{t}-p^{L}}{p^{H}-p_{t}}\right)+\ln p^{H}
$$

now $z_{t} \in R^{3}$.

We transform the raw data on $q_{t}$ using this transformation and then estimate the following $\operatorname{AR}(1)$ process for $z_{t}$ :

$$
z_{t}=A_{t}+\Gamma z_{t-1}+\varepsilon_{t}
$$

where $\varepsilon_{t} \sim N\left(0, \Sigma_{\varepsilon}\right), A_{t}$ is a deterministic time trend in transformed prices which we have set to be quadratic, i.e.

$$
A_{t}=a_{0}+a_{1} t+a_{2} t^{2}
$$

$\Gamma$ is a $3 \times 3$ matrix reflecting the influence of lagged prices on current period prices. We currently assume that the income process is independent of the house price and interest rate process. 
For the house price and interest rate data we use quarterly data from 197201 to 200503 , i.e. $t=1, \ldots, 135$ to estimate (5). Figures 1 and 2 show the actual and predicted series for these data.

Real house prices display low short term volatility but have large low frequency movements. Peaks occurred in 1974, 1981, 1990, and 2004. Troughs occurred in 1978, 1982 and 1995. Real prices rose more than 30\% from 1972 to 1974 , nearly $100 \%$ from 1986 to 1990 , and $100 \%$ from 1995 to 2004 . Prices fell $25 \%$ from 1974 to 1978 and $25 \%$ from 1990 to 1995.

Interest rates showed much more volatility over the period. In the 1970's real interest rates fluctuated dramatically ranging from a low of 0.84 in 1976 to a high of 1.03 toward the end of the decade. These swings were closely associated with large fluctuations in inflation rates. In the 1980's, real rates continued to display high frequency volatility but with much smaller amplitudes. This volatility declined further in the 1990's. This picture indicates that short term interest rate fluctuations are an important feature of the economic environment in which households make investment decisions.

For the income data we use quarterly average data from 1978 to 2003 for the each cohort $c \in\{1900, \ldots, 1980\} .{ }^{4}$ We estimated one income process for each cohort and for each education type. To conserve space, we only display the results for the 1940 cohort. The predicted and actual income processes are displayed in Figure 3. The figure shows the actual and predicted time series for those with only compulsory education ("low ed") and those with post-compulsory education ("high ed"). For both groups, income displays a "hump" shape over the lifecycle. The volatility in the figures indicates the time series volatility of the average in the population. We assume that income shocks are idiosyncratic and that therefore the individual level variance is simply the sample size multiplied by the variance of the population average.

\section{Shadow price of housing}

The shadow price of housing is the price of housing services that would lead a consumer who could separately purchase housing services and a housing asset to consume the same amount of housing services as the consumer who purchases the bundled product. If $\left(c_{t}, h_{t}\right)$ are the optimal choices of a consumer

\footnotetext{
${ }^{4}$ We define cohort $c$ to be the group of people with date of birth $d \in[c, c+10)$. That is, the cohort $c=1940$, is the set of people born between 1940 and 1950 .
} 
solving problem (1), then the shadow price $\phi_{t}$ satisfies

$$
\phi_{t}=\frac{u_{h}\left(c_{t}, h_{t}\right)}{u_{c}\left(c_{t}, h_{t}\right)}
$$

where $u_{h}$ and $u_{c}$ are the derivatives of the utility function with respect to $h$ and $c$.

Define $\lambda_{y t}$ and $\lambda_{h t}$ to be the Lagrange multipliers associated with the liquidity constraints in problem (1). The first order conditions from (1) give the shadow price $\phi_{t}$ as

$$
\phi_{t}=p_{t}\left(1-\frac{\beta \int \frac{p_{t+1}}{p_{t}} \frac{\partial V\left(w_{t+1}, q_{t+1}, t+1\right)}{\partial w} f\left(q_{t+1} \mid q_{t}\right) d q_{t+1}+\lambda_{h t} b_{h}}{\beta \int r_{t+1} \frac{\partial V\left(w_{t+1}, q_{t+1}, t+1\right)}{\partial w} f\left(q_{t+1} \mid q_{t}\right) d q_{t+1}+\lambda_{y t}+\lambda_{h t} b_{h}}\right) .
$$

Even when the liquidity constraints are not binding (i.e., the household does not want to borrow more) so $\lambda_{h t}=\lambda_{y t}=0$, this formula does not equal the user cost of housing capital. The shadow price in period $t$ depends on the current price of housing, the covariance of capital gains $\left(\frac{p_{t+1}}{p_{t}}\right)$ with the marginal utility of wealth, and the covariance of the interest rate with the marginal utility of wealth. The shadow price in (7) (and the associated value function) can be used to predict housing market behaviour and to measure the impacts on household welfare of changes in the housing market environment.

The shadow price only equals the user cost if consumers are risk neutral or if both interest rates and housing prices are deterministic. In these special circumstances, the user cost equals the shadow price which equals

$$
\phi_{t}=p_{t}\left(1-\frac{\int\left(\frac{p_{t+1}}{p_{t}}\right) f\left(q_{t+1} \mid q_{t}\right) d q_{t+1}}{\int r_{t+1} f\left(q_{t+1} \mid q_{t}\right) d q_{t+1}}\right) .
$$

The numerator is the expected capital gains. The denominator is the expected rate of return on financial assets. The user cost can be negative if expected capital gains are large enough. Assuming deterministic prices, this expression becomes

$$
\phi_{t}=p_{t}\left(\frac{r_{t+1}-g_{t+1}}{r_{t+1}}\right)
$$


where $g_{t+1}=p_{t+1} / p_{t}$.

Typically, empirical estimates of the user cost start with (8), measure $r_{t+1}$ using a weighted average of the mortgage interest rate, $i_{t+1}^{m}$, and an interest rate forgone on equity, $i_{t+1}^{e}$, add inflation $\rho_{t+1}$, income taxes $\tau_{t+1}$, a council tax rate $c_{t}$, and depreciation, $d_{t}$ to obtain an expression such as:

$$
\phi_{t}=p_{t}\left[\theta_{t} i_{t+1}^{m}+\left(1-\theta_{t}\right)\left[i_{t+1}^{e}\left(1-\tau_{t+1}\right)-\tau_{t+1} \rho_{t+1}\right]+c_{t}+d_{t}-g_{t+1}\right]
$$

where $\theta_{t}$ is the average mortgage advance divided by the house value. ${ }^{5}$

To show why the user cost is not useful for understanding housing market behaviour, we calculated the user cost in equation (9) for the UK using the Treasury bill rate, the Nationwide house price index, the Halifax mortgage interest rate and price data from the RPI. Figure 4 shows the results.

Between 1974-2002, the user cost fluctuated dramatically in response to changing real interest and capital gains rates. Peaks of $£ 13,805, £ 3,939$ and $£ 12,124$ were reached in 1974,1980 , and 1990. These corresponded to periods with high interest rates and/or low expected capital gains. Troughs of $-£ 7,117,-£ 1,888$, and $-£ 15,244$ were reached in 1976, 1986, and 2002, corresponding to episodes of high expected capital gains and/or low real interest rates.

If the user cost were equal to the shadow price of housing, households should have bought unlimited quantities of housing in the troughs where user cost was negative. Obviously, housing purchases were limited. Why? For two main reasons. Firstly, households were liquidity constrained - the amount they could borrow to purchase a house was limited. As can be seen in equation (7), when liquidity constraints are binding the Lagrange multipliers create a difference between the user cost and the shadow price. Secondly, future housing prices were uncertain. It would have been impossibly risky to buy arbitrarily large quantities of housing. This additional factor can lead the shadow price to be positive even when the user cost is negative. The user cost alone cannot predict consumer housing purchase behaviour nor measure fluctuations in welfare related to housing. What is required is the shadow price.

After calibrating our model, we discuss simulated shadow prices in Section 5.4 .

\footnotetext{
${ }^{5}$ The expression depends on inflation because of the interaction between the income tax, inflation, and the opportunity cost of equity. The time subscripts reflect our assumptions about timing.
} 


\section{Results}

Given the baseline parameters described, the model predicts household optimal choices of $\left(s_{t}, h_{t}\right)$ as functions of $\left(w_{t}, p_{t}, r_{t}, y_{t}, t\right)$. These functions are

$$
\begin{aligned}
h_{t} & =\pi_{1}\left(w_{t}, p_{t}, r_{t}, y_{t}, t\right) \\
s_{t} & =\pi_{2}\left(w_{t}, p_{t}, r_{t}, y_{t}, t\right) .
\end{aligned}
$$

In fact, the model produces one pair of functions for each cohort and for each education group. These policy functions describe the optimal choices of housing investment and savings as functions of beginning of period wealth, the price of housing, the interest rate, income and time. The model also predicts

$$
\begin{aligned}
u_{t} & =v\left(w_{t}, p_{t}, r_{t}, y_{t}, t\right) \\
\phi_{t} & =\Phi\left(w_{t}, p_{t}, r_{t}, y_{t}, t\right)
\end{aligned}
$$

where $\left(u_{t}, \phi_{t}\right)$ are the utility level obtained and the shadow price of housing and $(v, \Phi)$ are the value function and the shadow price function predicted by the model. We discuss each of these functions in the following sections.

\subsection{Policy functions, welfare and shadow prices}

It is not possible to display or describe these functions in full detail. Instead we discuss the policy functions, the value function and shadow prices for the 1940 cohort with high education at age $42(\mathrm{t}=23$ in our model and calendar year 1987.) Given fixed values of income and the interest rate (both fixed at the mean levels), the dependence of these functions on wealth and prices are displayed in Figures 9-12. Figure 9 displays the consumption function, Figure 10 the housing function, Figure 11 the value function and Figure 12 the shadow price of housing. All pictures display wealth on the horizontal axis measured in units of $£ 100,000$. That is, one unit of wealth equals $£ 100,000$.

Figure 9 shows how consumption varies with wealth and current house price. The figures show that consumption increases from $£ 10,000$ when wealth is $£ 13,000$ to about $£ 22,000$ when wealth is about $£ 50,000$. The picture shows that large increases in house prices have very small impacts on consumption demand when wealth is small $(<£ 50,000)$ but larger impacts when wealth is large $(>£ 50,000)$. In the latter case, increases in the house price increases consumption demand. Note that pictures show the effect of 
house price changes holding (nominal) wealth constant where wealth includes the value of owner occupied housing. Thus they allow for an ordinary income effect (due to the price change) but not for an endowment income (or wealth) effect. In an analogous way Figure 10 show the effects of wealth and prices on housing demand. In this case, housing demand increases strongly with wealth and decreases strongly with price. Again these house price effects contain no wealth effects.

Several influences underlie these results. First, when house prices increase, there is a substitution effect. People want to consume more consumption and less housing. Second, because of the assumptions on the house price process, when housing prices are low, the expected return on housing is high. People want to own more housing when house prices are low and less housing when they are high. Third, because of liquidity constraints, when house prices are low, a household must purchase a large house to borrow from the future. When prices are high, a smaller house purchase is sufficient for the same quantity of borrowing. The combination of these three forces explains the house price effects.

\subsection{Welfare and shadow prices}

The results from the model can also be used to calculate the welfare impacts on households of changes in wealth, prices, interest rates and income. One can also study the shadow price of housing (the marginal utility valuation of one additional unit of housing).

Figure 11 records the value function as a function of prices and wealth conditional on fixed values of the interest rate and income. Figure 12 displays the shadow price of housing as a function of prices and wealth, again with the interest rate and income fixed. The value function is an increasing, strongly concave function of wealth and a decreasing function of the current house price. The imapct of house prices on welfare are small for household with the lowest wealth, stronger for the households with high wealth, and strongest for households with wealth between about $£ 5,000$ and $£ 20,000$. Again, these house price effects strip out any wealth effects and measure the net impact of house prices on utility due to: the increased cost of the housing good; the relaxed constraint on borrowing, and; impacts of current price on beliefs about future asset returns and risks.

The shadow price of housing is given by equation (7). Figure 12 shows the shadow price for this cohort. The shadow price is an increasing function 
of the current housing price. The effect of prices is stronger when wealth is low and is much stronger when wealth is very low ( less than $£ 10,000$ or $£ 20,000)$. The shadow price is also a decreasing, convex function of wealth. When wealth is larger than about $£ 45,000$ it is flat. When wealth is less than 10 or 20,000 , the magnitude of the slope increases dramatically.

\subsection{Lifeycle simulations}

What do these results imply for aggregate time series of consumption, housing, and wealth or for the dynamics of household welfare and of the shadow price of housing? To answer these questions, we used our model to simulate an economy with 1000 agents each facing one of ten different regional price series. From this simulated economy we then simulated lifeycle paths of consumption, housing and wealth and of household welfare and the shadow price of housing.

Figures 13 - 44 display lifecycle profiles for each cohort and for each education group. For each group, we show the mean and distribution of simulated wealth, housing demand, consumption demand, utility, and the shadow price for the period 1990 to 2007 as well. For example, Figures 29-32 display results for the 1940 cohort with both low and high education from model period 26 to 46 (that is age 45 - 65 and for years 2010). In the simulated data, average wealth for both groups increased from near zero to $£ 100,000$. The spread between the $10 \%$ quantile and the $90 \%$ quantile of the welath distribution ranges from about $£ 50,000$ to about $£ 150,000$ for the low education group and from about $£ 80,000$ to $£ 200,000$ for the high education group. At the same time, average housing demand is hump-shaped and consumption grows from less than $£ 20,000$ to more than $£ 50,000$. This growth in wealth and consumption implicitly assumes that these households forecast a large part of the house price growth of this period.

Similar patterns can be seen in the depicted profiles for the other cohorts.

\subsection{Shadow prices and expenditure}

We can used either (6) or (7) to calculate the shadow price. Equation (6) shows that it can be calculated directly using the parameters, optimal con- 
sumption and housing demand. Equation (6) can be written

$$
\begin{aligned}
\phi_{t} & =\frac{1-\alpha}{\alpha} \frac{c_{t}}{h_{t}} \\
& =\frac{1}{4} \frac{c_{t}}{h_{t}} .
\end{aligned}
$$

Further housing expenditure is

$$
\begin{aligned}
e_{t}^{h} & =\phi_{t} h_{t} \\
& =\frac{1}{4} c_{t}
\end{aligned}
$$

The first things to notice about the shadow prices in the model are that they are always positive and relatively stable within cohorts, across cohorts and across the lifecycle. For all cohorts, the time series of shadow prices are of the order of 0.2 and are relatively flat over the lifeycycle. They seem to be somewhat higher for the younger cohorts at young ages and for the older cohorts at older ages. Also, there is much more variability in the shadow prices for both younger cohorts and older cohorts. Both of these latter effects are due to binding constraints being more important for these groups.

The profiles of housing expenditures are simply $25 \%$ of the consumption profile. The younger cohorts consumption and housing expenditure is much more volatile.

\subsection{Parameter impacts}

We also studied how changes in the parameters affect the results. Key drivers of the results in the model include household beliefs about the house, price, and income processes and the parameters of the liquidity constraints. To investigate the importance of the parameters we also computed results for three alternative models. The differences from the baseline model are described in Table 1.

Table 1:

Alternative models

\begin{tabular}{|c|c|c|}
\hline Model & Description & \multicolumn{1}{|c|}{ Question } \\
\hline A & Eliminate trend growth in house price process. & Impact of beliefs on house prices? \\
B & Loose liquidity constraints $\left(b_{y 1}=5, b_{h 1}=0.95\right)$ & Impact of relaxed liquidity constraints \\
C & Tight liquidity constraints $\left(b_{y 1}=2.5, b_{h 1}=0.5\right)$ & Impact of tight liquidity constraints? \\
\hline
\end{tabular}


In Model A, we eliminate the trend growth rate in housing prices. This results in significantly lower values of expected house price growth. There still is some expected house price growth because the house price is an exponential function of a shock. We report results of this experiment for the 1940 Cohort, High Education group. Results of this experiment are summarised in Figures 45 and 46 . These can be compared with the baseline results for this group in Figures 31 and 32. As one would expect, the growth in wealth in this model is much smaller. Also, cross-sectional variability in wealth is much smaller. Also housing consumption in the low growth model is roughly half as large as housing consumption in the baseline model. In terms of welfare, utility is higher in the high expected house price growth world.

In Model B, we investigate the impact of relaxed liquidity constraints. A summary of these results is shown in Figures 47 and 48 . With relaxed constraints, household wealth grows much more quickly. The median level reaches $£ 150,000$ by model period 32 versus $£ 110,000$ in the baseline model. After that, median and $90 \%$ quantile wealth levels remain higher throughout life. Much of this increased wealth is supported by larger investment in housing than the baseline model and in turn supports a higher consumption level than the baseline model. Also, the cross sectional variation in housing consumption is much larger in Model B than in the baseline model. Figure 50 displays the impact on utility and on the shadow price. Utility is significantly higher in the model with relaxed constraints as one would expect. This difference diminishes near the end of life. Also the cross-sectional variation of utility is higher than the baseline model. For the shadow price, the shadow price is somewhat lower at young ages. But then the $90 \%$ quantile increases dramatically at older ages as the fraction who are constrained increases.

Results from Model $\mathrm{C}$ are displayed in Figures 49 and 50. The differences from the baseline model are less stark but are visible. Average investment in housing is higher in model $\mathrm{C}$ at younger ages. Larger quantities are required to borrow than in the baseline model. The cross-sectional variation in housing consumption is also larger at young ages. Those who are more constrained are likely to invest more in housing in order to borrow. The impact on utility is unclear. Everything else equal, tight constraints cannot increase ex ant utility however, could lead to ex post higher utility is household behaviour is forced to be more conservative. 


\section{Conclusion}

In this paper we calibrate a lifecycle model of demand for housing. The model has stochastic house prices, interest rates, and incomes along with constraints on borrowing that depend on household income and on the house value. The model is calibrated to parameters from the literature and to data from the UK FES/EFS. We use the model to study how demand for housing and consumption as well as the welfare depend on wealth, house prices, interest rates, income, age and birth cohort. We also use the model to estimate shadow prices for housing.

We find that house prices (excluding endowment income effects) have small impacts on consumption but that wealth impacts on consumption are significant. Both house price impacts and wealth impacts on housing demand are significant. The shadow price of housing is an increasing function of house prices. The impact is stronger when wealth is low.

We also simulate lifecycle profiles for 18 groups, 9 cohorts and 2 education groups per cohort. The model produces reasonable lifecycle profiles of consumption and housing demand.

We find that reduced expectations about house price growth reduce investment in housing and reduce the rate of wealth accumulation. We also find that either tightening or loosening liquidity constraints have impacts on housing, wealth and utility as one would expect.

Much work remains to be done to improve the modeling approach. First, more work can be done to fit the model to data. Our work in this dimension was limited by data quality and computational considerations. Second, further investigations about alternative assumptions about the stochastic processes driving the model are required. Finally, several features of the housing market can be added to the model including transaction costs, taxes, depreciation and maintenance, choice of rental vs. ownership., and alternative assumptions about credit market conditions. These features can be incorporated in the present model and offer several promising avenues for future work. 


\section{A Tables}

Table A.1:

Summary of notation

\begin{tabular}{|c|l|}
\hline Variable & \multicolumn{1}{|c|}{ Description } \\
\hline$w_{t}$ & total wealth at $t$ \\
$h_{t}$ & quantity of housing at $t$ \\
$c_{t}$ & quantity of other consumption at $t$ \\
$s_{t}$ & bank savings (or borrowing) at $t$ \\
$p_{t}$ & price of housing at $t$ \\
$r_{t}$ & gross interest rate at $t$ \\
$y_{t}$ & income at $t$ \\
$q_{t}$ & vector of $\left(p_{t}, r_{t}, y_{t}\right)$ \\
$w_{t}^{L}$ & minimum feasible wealth level (see section 10 on bankruptcy) \\
\hline
\end{tabular}


Table A.2:

Baseline Parameter Values

\begin{tabular}{|lcc|}
\hline \multicolumn{1}{|c|}{ Parameter } & Symbol & Value \\
\hline Preferences & & \\
\hline Curvature of utility & $\sigma$ & -1 \\
Marginal value of bequests & $\beta_{T}$ & 0.98 \\
Discount rate & $\beta$ & 0.98 \\
Consumption share & $\alpha$ & 0.7 \\
\hline Liquidity constraints & & \\
Income constraint (1) & $b_{y 0}$ & 0 \\
Income constraint (2) & $b_{y 1}$ & 3.5 \\
House value constraint (1) & $b_{h 0}$ & 0.1 \\
House value constraint (2) & $b_{h 1}$ & 0.8 \\
\hline
\end{tabular}


Table A.3:

Ratio of mortgage advance to income: Quantiles

\begin{tabular}{|cccc|}
\hline Year & $75 \%$ & $90 \%$ & $95 \%$ \\
\hline 1990 & 2.74 & 3.2 & 3.62 \\
1991 & 2.74 & 3.14 & 3.50 \\
1992 & 2.72 & 3.06 & 3.26 \\
1993 & 2.75 & 3.07 & 3.25 \\
1994 & 2.78 & 3.12 & 3.28 \\
1995 & 2.79 & 3.13 & 3.3 \\
1996 & 2.6 & 3.04 & 3.27 \\
1997 & 2.67 & 3.12 & 3.37 \\
1998 & 2.68 & 3.13 & 3.4 \\
1999 & 2.75 & 3.22 & 3.49 \\
2000 & 2.77 & 3.26 & 3.54 \\
2001 & 2.77 & 3.31 & 3.63 \\
\hline
\end{tabular}

Note: Column 2 is the $75 \%$ quantile of the distribution of mortgage advances to total income. Column 3 is the $90 \%$ quantile. Column 4 is the $95 \%$ quantile. The sample is all mortgages recorded in the Survey of Mortgage Lenders 1990 to 2001. 
Table A.4:

Ratio of mortgage advance to house value:

Quantiles

\begin{tabular}{|ccccc|}
\hline Year & $50 \%$ & $75 \%$ & $90 \%$ & $95 \%$ \\
\hline 1990 & .85 & .960 & 1.00 & 1.00 \\
1991 & .85 & .950 & 1.00 & 1.00 \\
1992 & .878 & .950 & .966 & 1.00 \\
1993 & .875 & .950 & .960 & 1.00 \\
1994 & .893 & .950 & .966 & 1.00 \\
1995 & .9 & .950 & .967 & 1.10 \\
1996 & .900 & .950 & .965 & 1.00 \\
1997 & .890 & .950 & .965 & 1.16 \\
1998 & .872 & .950 & .950 & .971 \\
1999 & .852 & .950 & .950 & .967 \\
2000 & .843 & .949 & .963 & .972 \\
2001 & .741 & .900 & .950 & .970 \\
\hline
\end{tabular}

Note: Column 2 is the $50 \%$ quantile of the distribution of mortgage advances to total income. Column 3 is the $75 \%$ quantile. Column 4 is the $90 \%$ quantile. Column 5 is the $95 \%$ quantile. The sample is all mortgages in the Survey of Mortgage Lenders 1990 to 2001. 
Table A.5:

House values (1992 - 1999):

FES cohort averages

\begin{tabular}{|cccc|c|}
\hline Cohort & Education & Age & House value & Calibrated wealth \\
\hline 1900 & 0 & 91 & 93,500 & 79,950 \\
1900 & 1 & 91 & 162,000 & 177,000 \\
1910 & 0 & 81 & 82,900 & 63,600 \\
1910 & 1 & 81 & 127,000 & 125,000 \\
1920 & 0 & 71 & 78,200 & 25,100 \\
1920 & 1 & 71 & 123,000 & 73,000 \\
1930 & 0 & 61 & 78,700 & $-16,600$ \\
1930 & 1 & 61 & 122,000 & 12,000 \\
1940 & 0 & 51 & 81,500 & $-20,000$ \\
1940 & 1 & 51 & 125,000 & $-1,500$ \\
1950 & 0 & 41 & 080,200 & $-20,000$ \\
1950 & 1 & 41 & 113,000 & $-3,000$ \\
1960 & 0 & 31 & 71,200 & $-20,000$ \\
1960 & 1 & 31 & 90,400 & $-20,000$ \\
1970 & 0 & 21 & 57,400 & 92,500 \\
1970 & 1 & 21 & 65,500 & 32,600 \\
\hline
\end{tabular}




\section{B Computation}

Let $V\left(w_{t}, q_{t}, t\right)$ be the value function for a household in period $t$ with wealth $w_{t}$ facing prices $q_{t}$ where $q_{t}=\left(p_{t}, r_{t}, y_{t}\right) .{ }^{6}$ That is, $V$ measures the maximum level of utility or welfare obtainable by a household when wealth is $w$ and prices are $q$ in period $t$. Further let $c\left(w_{t}, q_{t}, t\right), s\left(w_{t}, q_{t}, t\right)$, and $h\left(w_{t}, q_{t}, t\right)$ be the optimal policy functions of such a household. These describe optimal choices of consumption, savings, and housing as functions of wealth, prices, and time.

Our computational methods compute numerical approximations to these four functions. Because the approximation technique for each of the four functions is similar. We only detail approximation of the value function $V$. We will approximate $V$ with the function

$$
\widehat{V}(w, q, t)=\sum_{j=1}^{J} a_{j}(t) \phi_{j}(w, q)
$$

where the functions $\phi_{j}(w, q) j=1, \ldots, J$ are suitably chosen basis functions (tensor products of univariate spline functions) and the coefficients $a_{j}(t)$ $j=1, \ldots, J$ are computed by solving the problem

$$
\min _{\{a\}}\left\{\sum_{i=1}^{N} \omega_{i}\left[V\left(w_{i}, q_{i}, t\right)-\sum_{j=1}^{J} a_{j}(t) \phi_{j}\left(w_{i}, q_{i}\right)\right]^{2}\right\}
$$

where $\left\{\omega_{i}\right\}_{i=1}^{N}$ are appropriately chosen weights.

The following algorithm is used to compute these approximations.

1. Fix a grid $\left(w_{i}, q_{i}\right)$ for $i=1, \ldots, N$. Each point in this grid is an element of $R^{4}$.

2. Fix a set of basis functions $\phi_{j}(w, q)$ for $j=1, \ldots, J$.

3. Set $t=T$.

4. For each $i$, set $w_{T}=w_{i}$ and $q_{T}=q_{i}$ and compute the solution to the household's period $T$ problem. The result is a set of values for the value function $V\left(w_{i}, q_{i}, T\right)$.

\footnotetext{
${ }^{6}$ When there are no fixed costs, the value function does not depend on $h$ explicitly.
} 
5. Compute the coefficients $a_{j}(T)$ that solve problem (10).

6. Set $t=T-1$.

7. For each $i$, set $w_{T-1}=w_{i}$ and $q_{T-1}=q_{i}$ and compute the solution to the household's period $T-1$ problem with $\widehat{V}(w, q, T)$ replacing $V(w, q, T)$ and with the integral computed by Gaussian quadrature techniques. The result is a set of values for the value function $V\left(w_{i}, q_{i}, T-1\right)$.

8. Compute the coefficients $a_{j}(T-1)$ that solve problem $(10)$.

This process is repeated for each period. In practice, values for the policy functions are saved as well and the actual grid chosen varies with each period.

Additionally, our baseline model requires us to approximate a three dimensional integral. We approximate this using Gaussian quadrature. Extensions to the baseline model require approximation of a six dimensional integral. Again we will use Gaussian quadrature to approximate these integrals.

Compute code for this model is published can be found at 


\section{References}

[1] Attanasio, O., Blow, L., Hamilton, R., and A. Leicester (2004), "Booms and Busts: Consumption, House Prices and Expectations," Bank of England Working Paper.

[2] Attanasio, O. and Weber, G. (1994), "The UK Consumption Boom of the Late 1980's: Aggregate Implications of Microeconomic Evidence," The Economic Journal, 104(427): 1269-1302.

[3] Banks, J., Blundell, R., Smith, J., and Z. Smith (2004), "House Price Volatility and Housing Ownership over the Lifecycle," University College London, Department of Economics Discussion Paper 04-09.

[4] Blundell, R., Browning, M. and C. Meghir (1994), "Consumer Demand and the Life-Cycle Allocation of Household Expenditure", Review of Economic Studies, 61, 57-80.

[5] Campbell, John and Cocco, João (2007), "How Do House Prices Affect Consumption: Evidence from Microdata," Journal of Monetary Economics, 54: 591-621.

[6] Crawford, I. (1994), "UK household cost-of-living indices, 1979-1992", Institute for Fiscal Studies Commentary C44.

[7] Deaton, A. (1991), "Saving and Liquidity Constraints", Econometrica, 59(5): 1221-1248.

[8] Díaz, Antonia, and Luengo-Prado, María José (2007), "On the User Cost and Homeownership," Review of Economic Dynamics, 11: 584-613.

[9] Disney, R., Henley, A. and Jevons, D. (2003) "House price shocks, negative equity and household consumption in the UK", mimeo, University of Nottingham.

[10] Fernandez-Villaverde, J. and D. Krueger (2001), "Consumption and Saving over the Life Cycle: How Important are Consumer Durables?", mimeo.

[11] Goodman, A. and Oldfield, Z. (2004) "Permanent differences? Income and expenditure inequality in the 1990s and 2000s", IFS Reports, R66. 
[12] Judd, K. (1998), Numerical Methods in Economics, The MIT Press: Cambridge.

[13] Li, Wenli and Yao, Rui (2007), "The Life-Cycle Effects of House Price Changes," Journal of Money, Credit and Banking, 39(6): 1375-1409.

[14] Muellbauer, J. and A. Murphy (1997), "Booms and Busts in the UK Housing Market," The Economic Journal, 107(445): 1701-1727.

[15] Nesheim, Lars. and Skrainka, Ben (2009), "Fortran Code to Simulate a Lifecycle Housing Model," CEMMAP Software CS2009/01, http:// cemmap.ac.uk.

[16] Poterba, J. (1992), "Taxation and Housing: Old Questions, New Answers," The American Economic Review, 82(2): 237-242.

[17] Robinson, B. and Skinner, T. (1989), "Reforming the RPI: a better treatment of housing costs". 
Figure 1

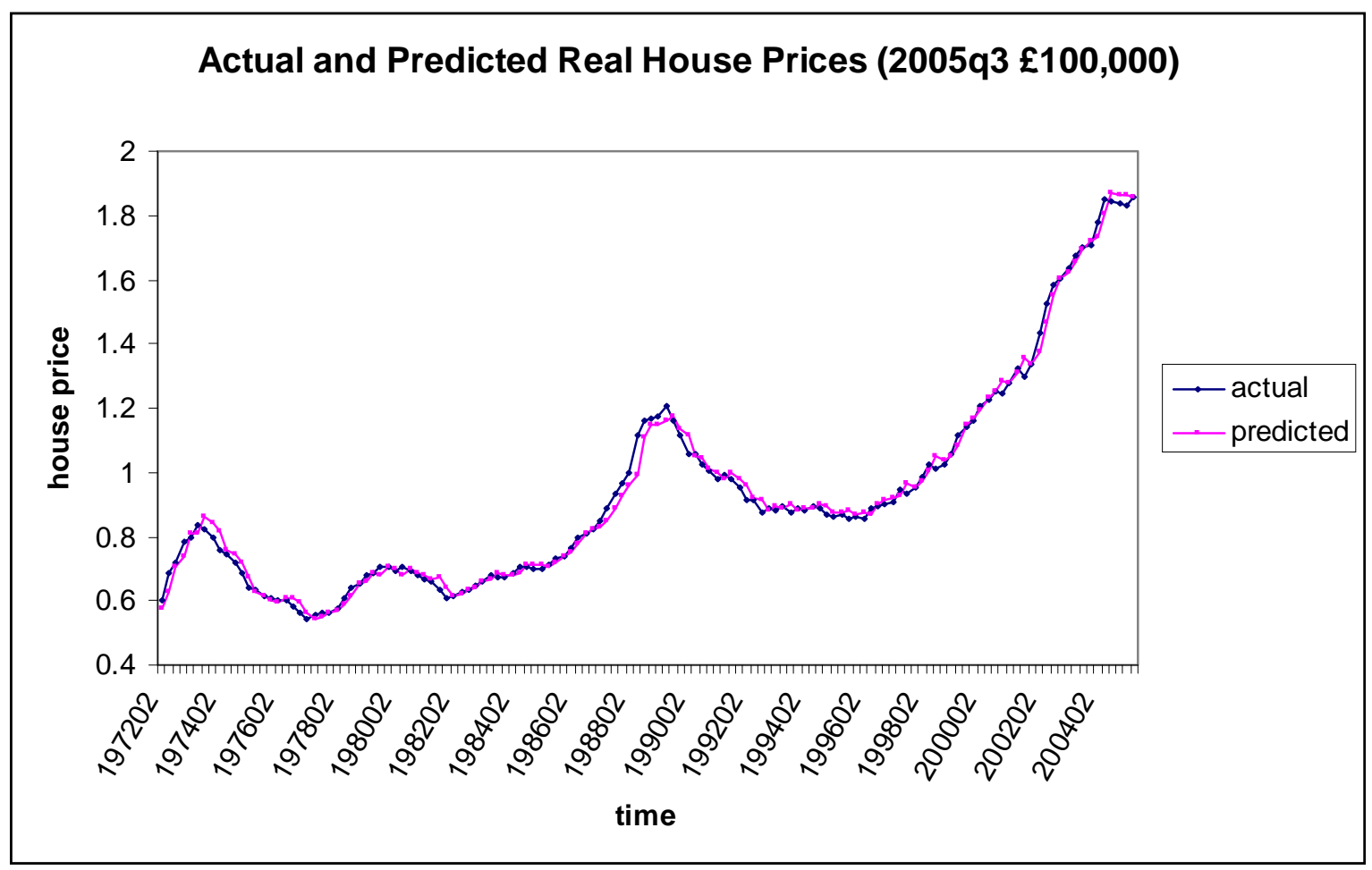


Figure 2

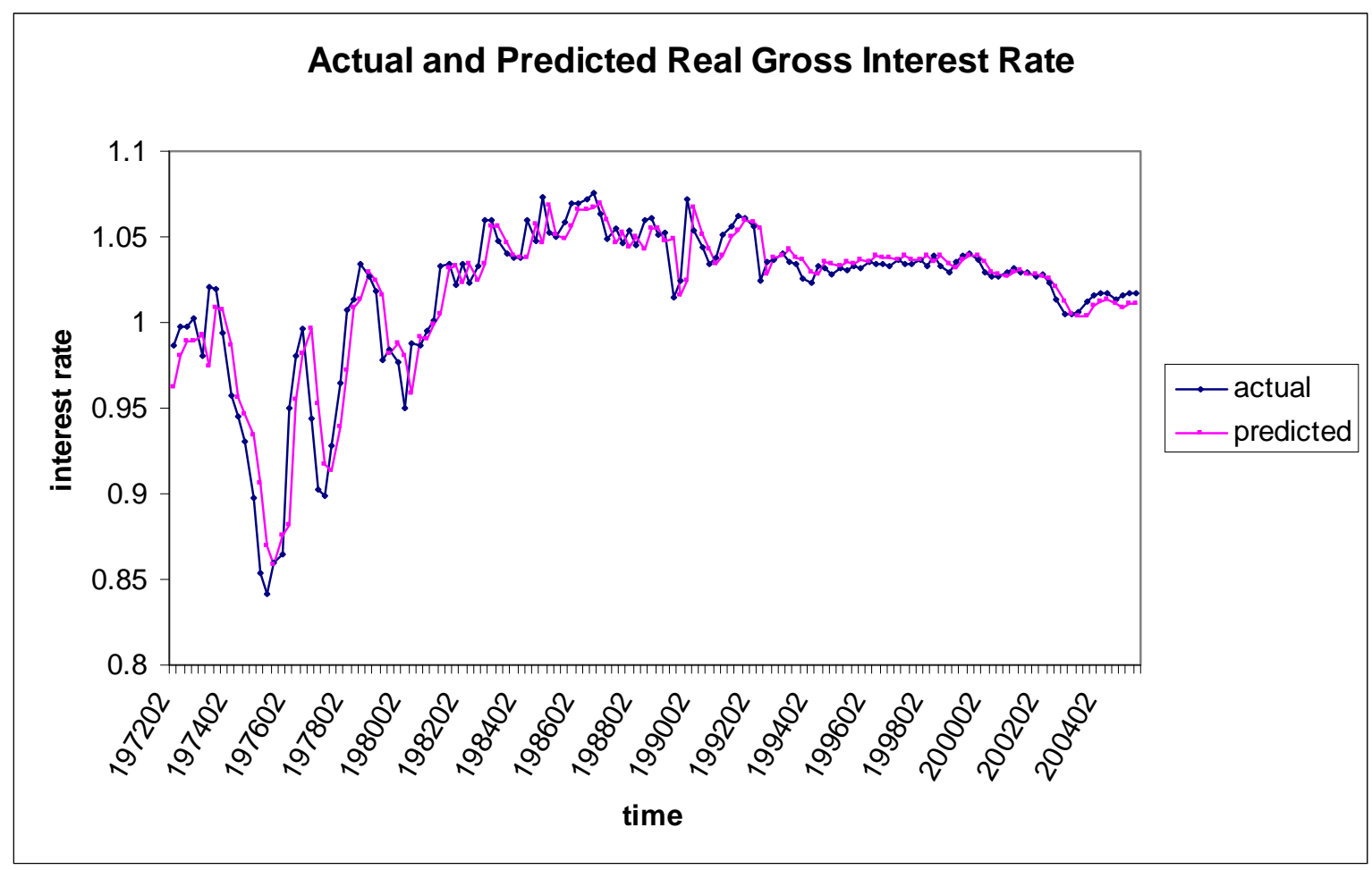


Figure 3
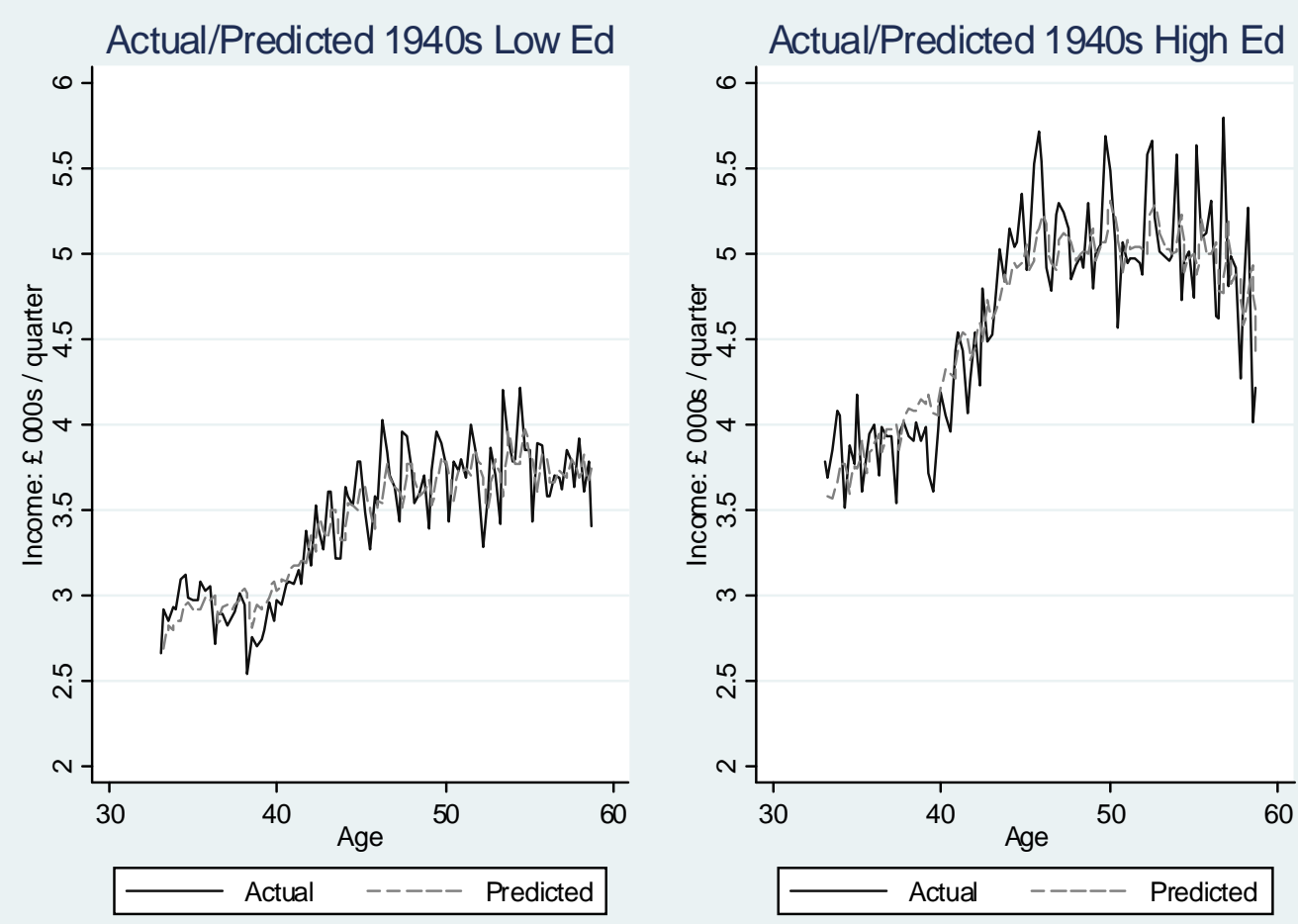
Figure 4

User cost of housing capital in Great Britain (2002£)

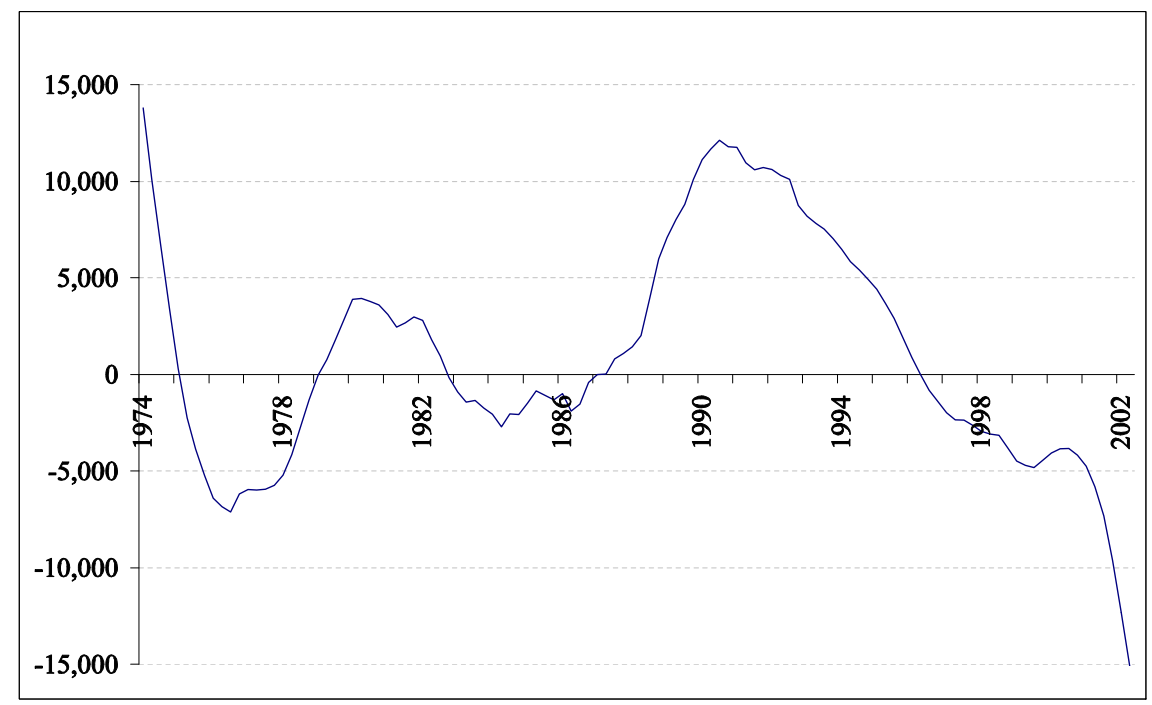


Figure 5

Predicted household size: Older cohorts, compulsory education

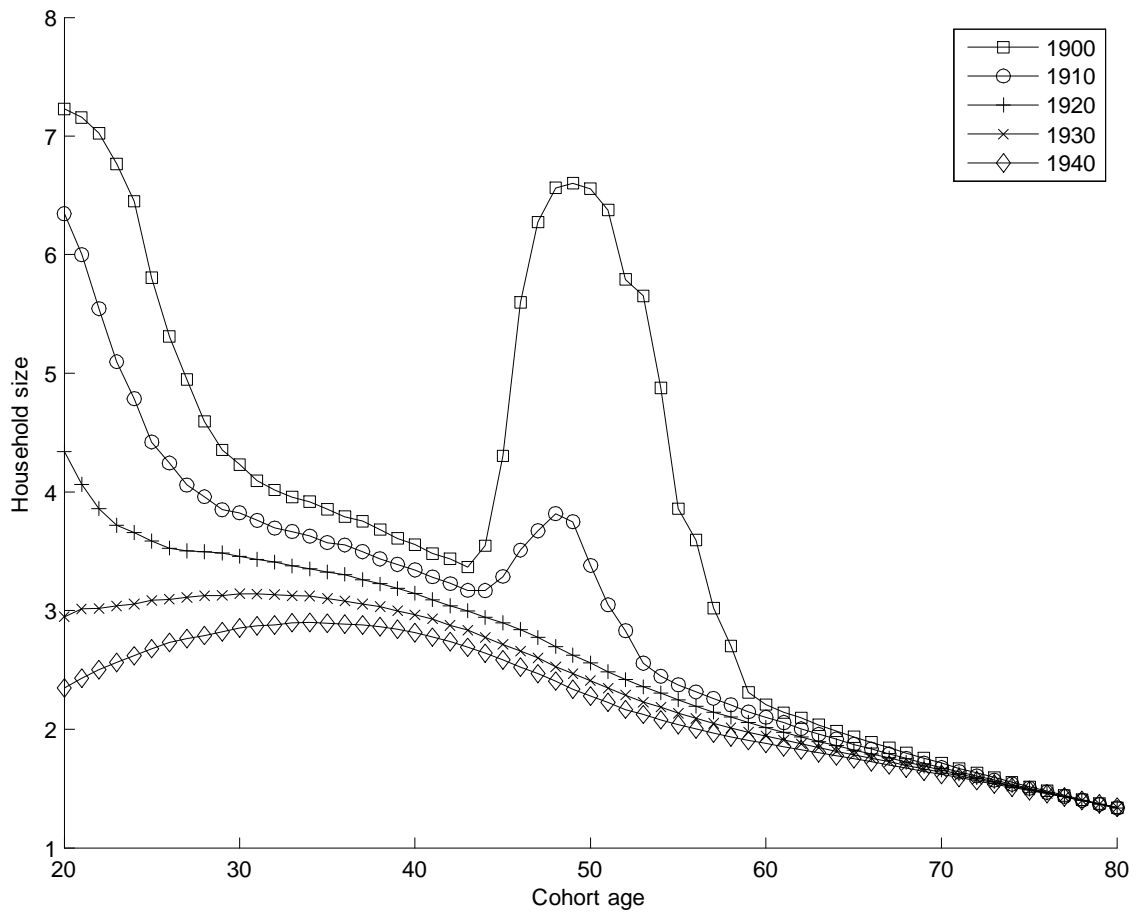




\section{Figure 6}

Predicted household size: Younger cohorts, compulsory education

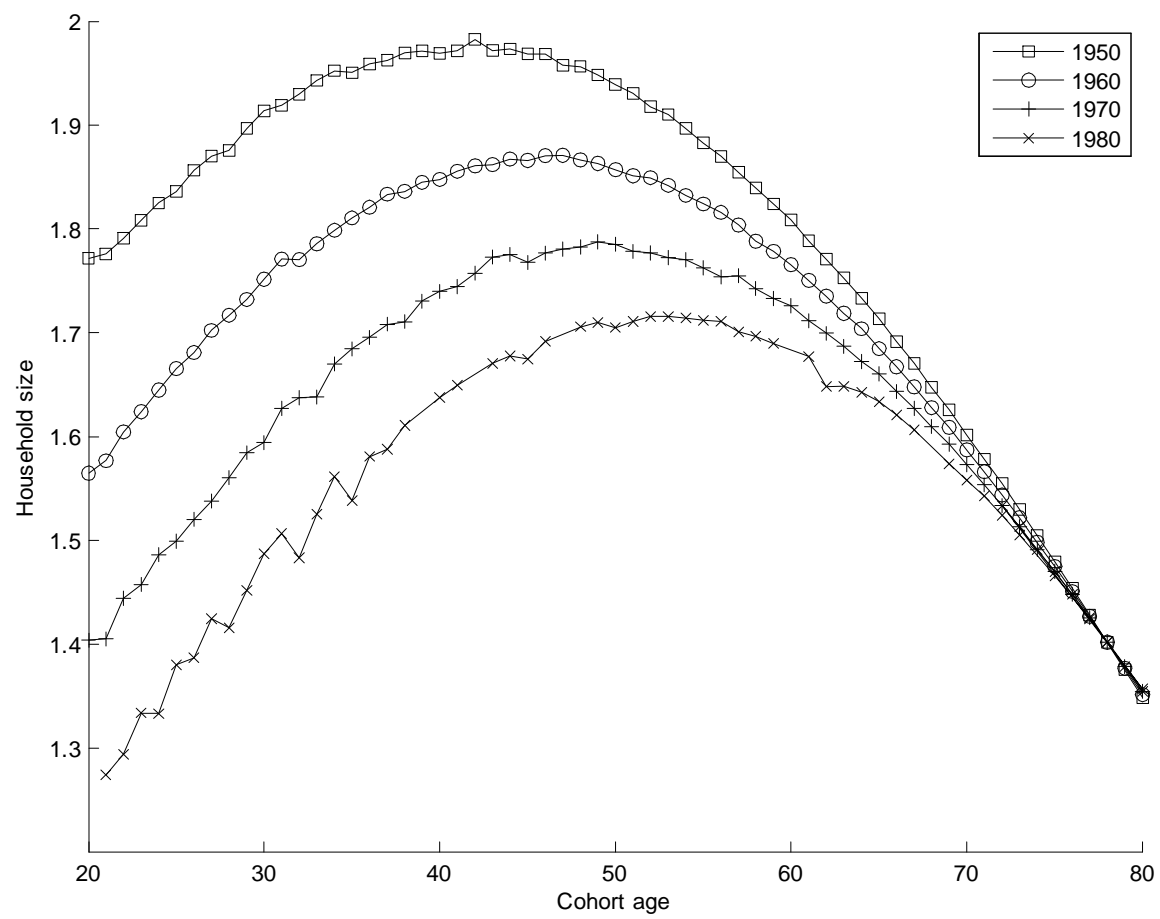


Figure 7

Predicted household size: Older cohorts, advanced education

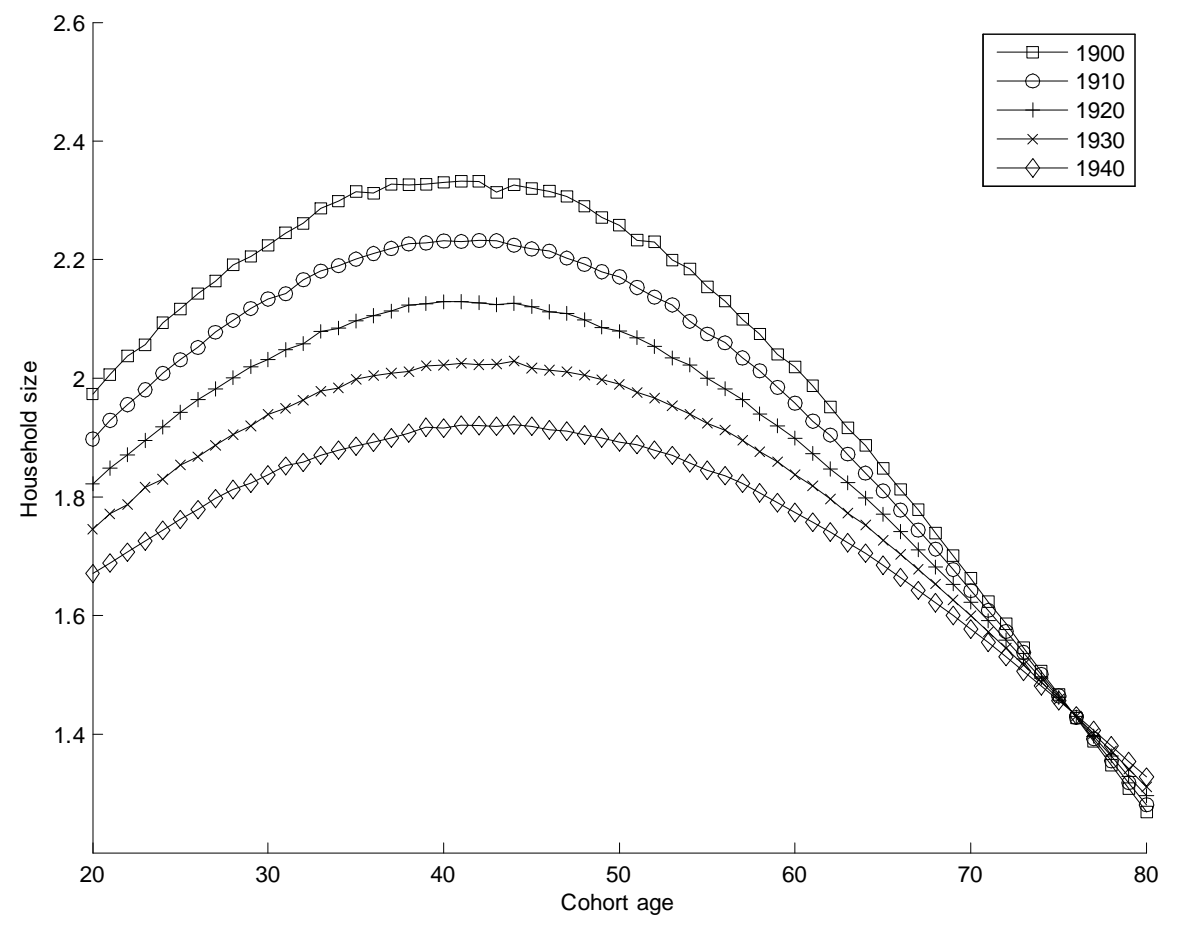




\section{Figure 8}

Predicted household size: Younger cohorts, advanced education

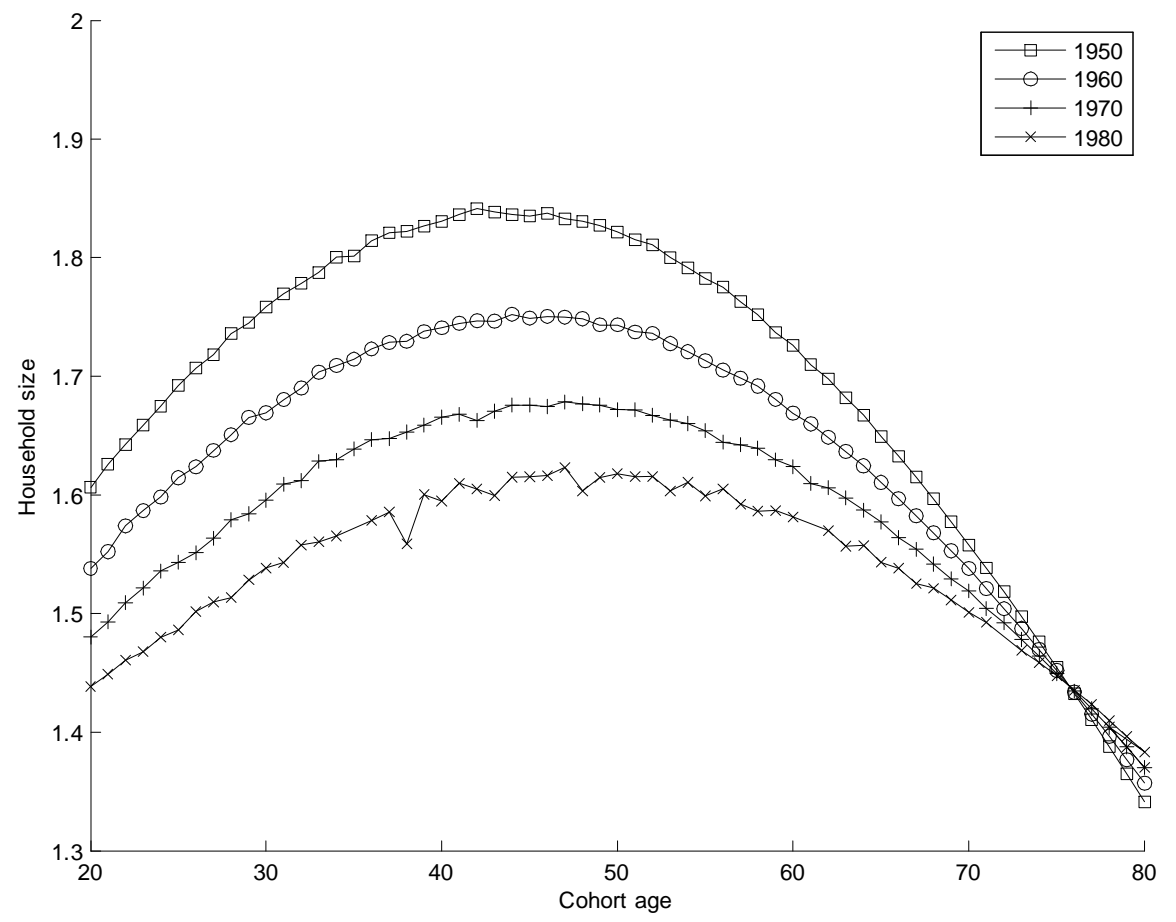




\section{Figure 9}

Optimal consumption: 1940 cohort, high education. One unit of wealth of consumption equals $£ 100,000$.

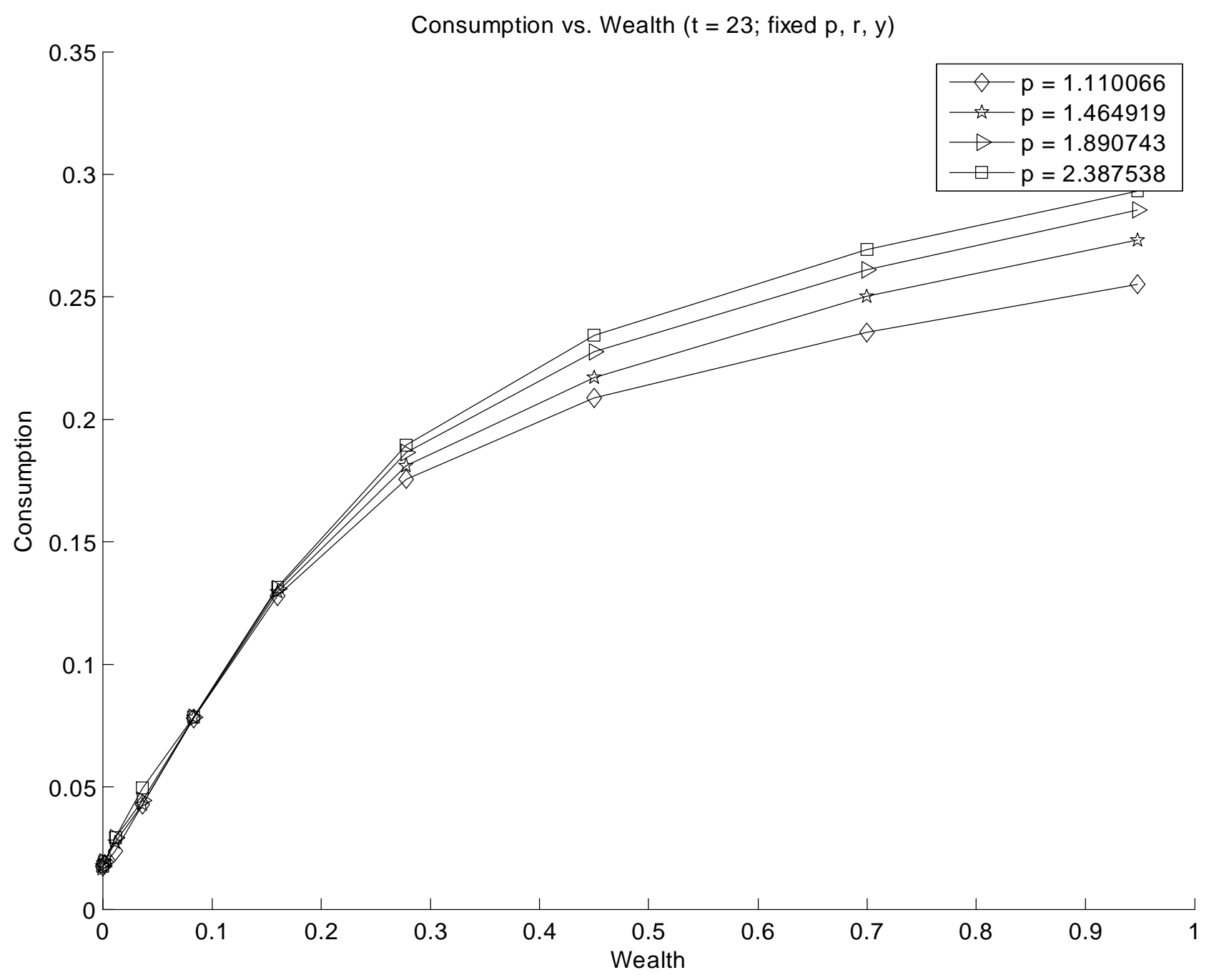


Figure 10

Optimal housing: 1940 cohort, high education. One unit of wealth equals $£ 100,000$.

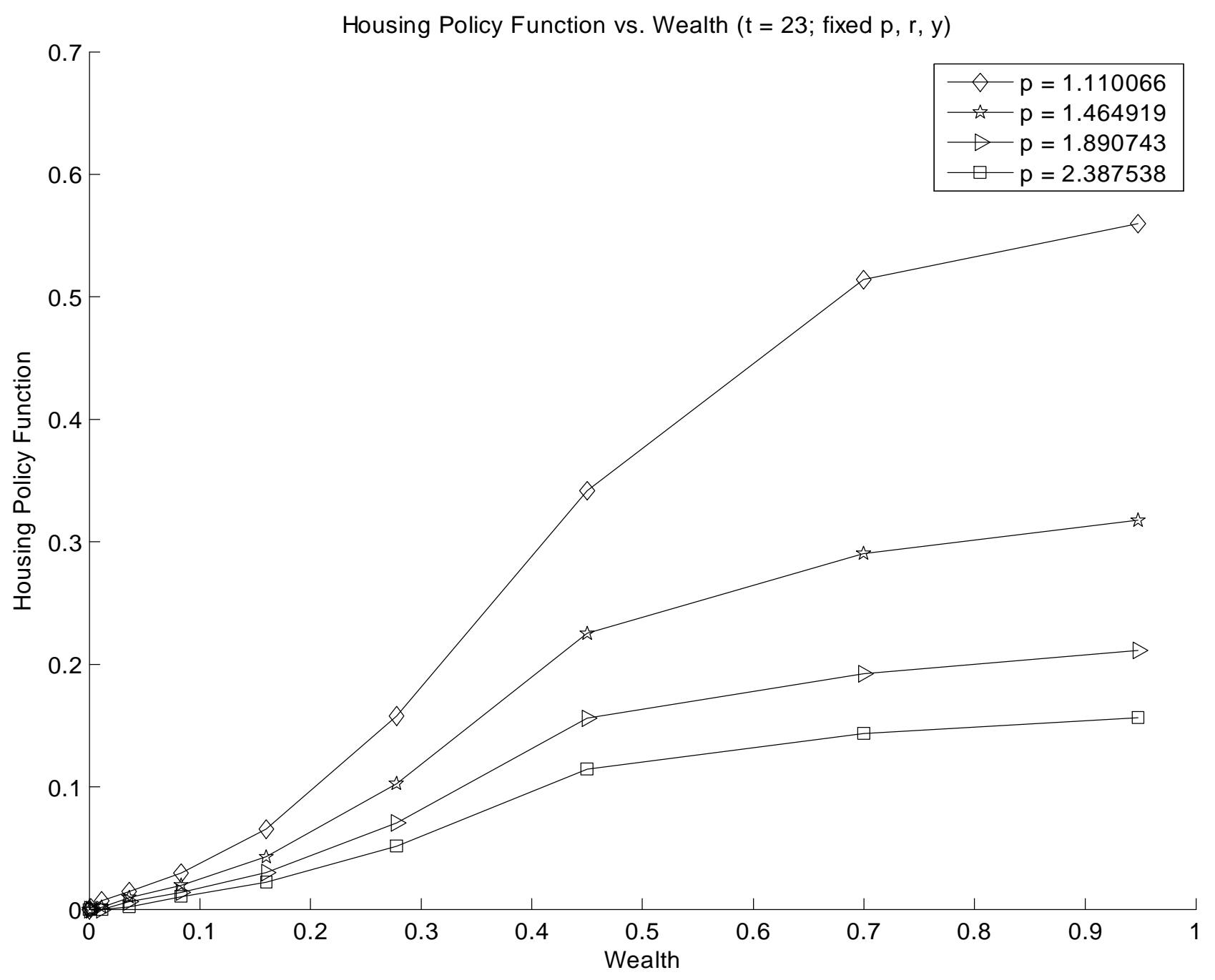


Figure 11

Utility: 1940 cohort, high education. One unit of wealth equals $£ 100,000$.

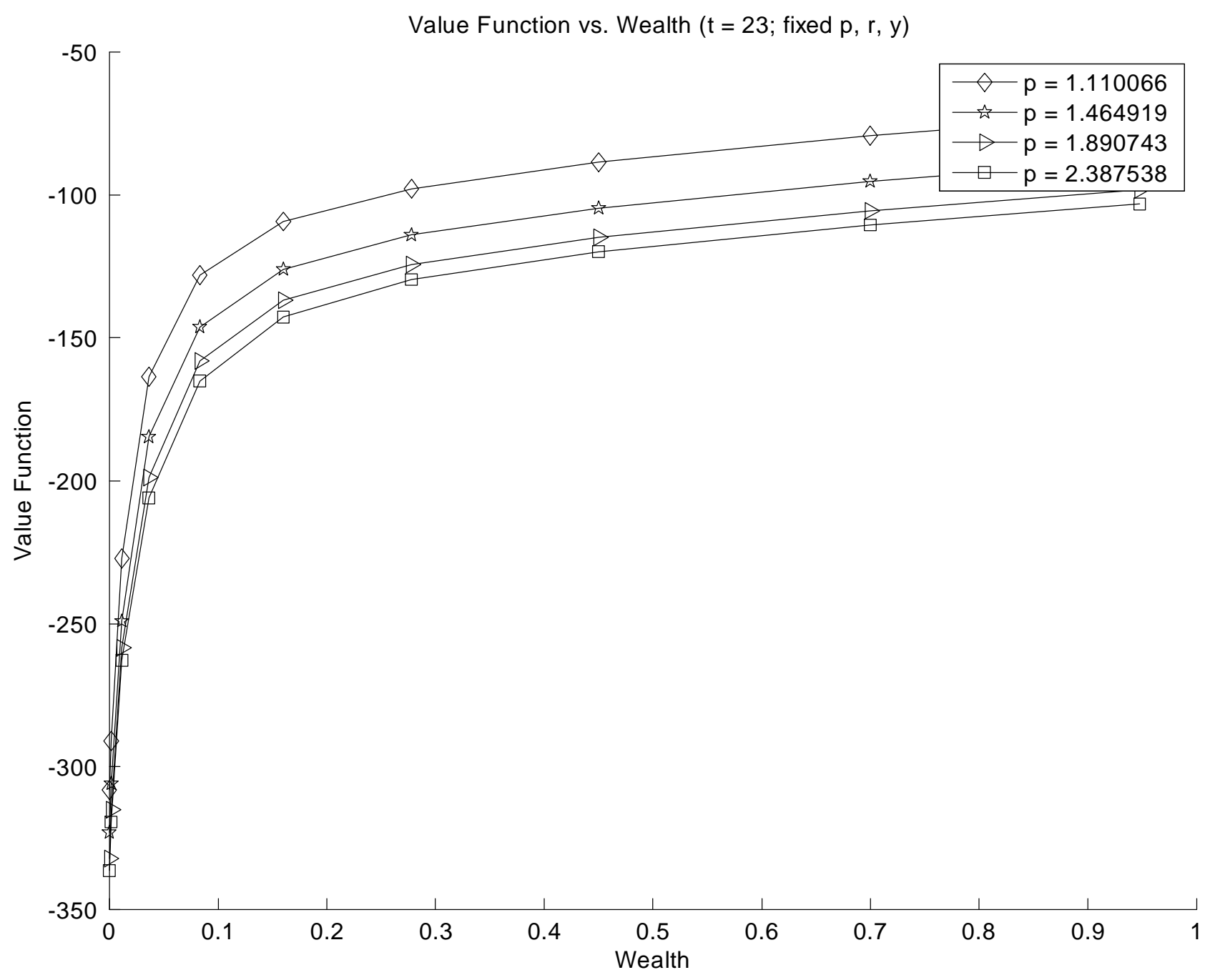


Figure 12

Shadow price: 1940 cohort, high education. One unit of wealth equals $£ 100,000$.

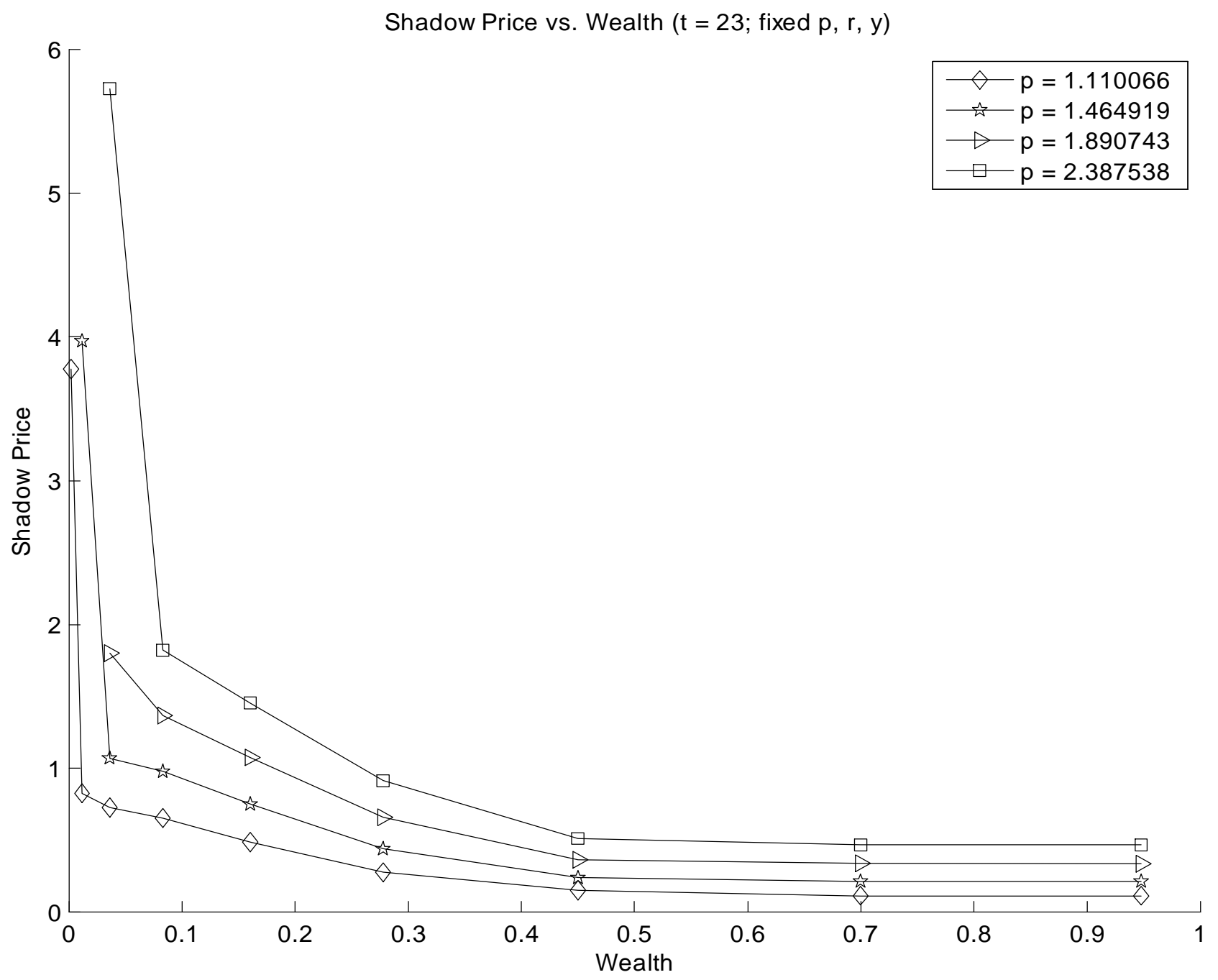


Figure 13

Wealth, housing and consumption: 1900 Cohort, Low Education
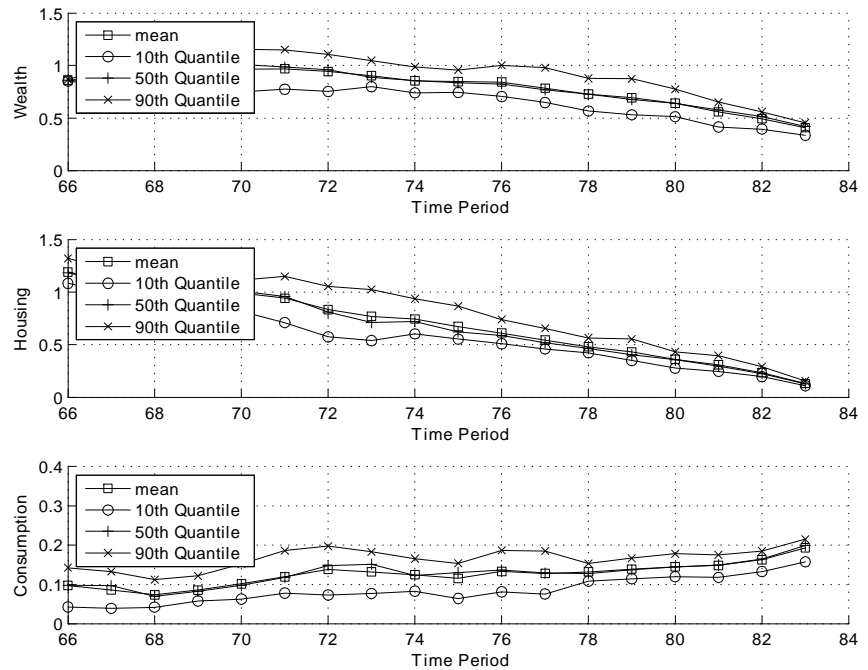

Figure 14

Utility and the shadow price: 1900 Cohort, Low Education
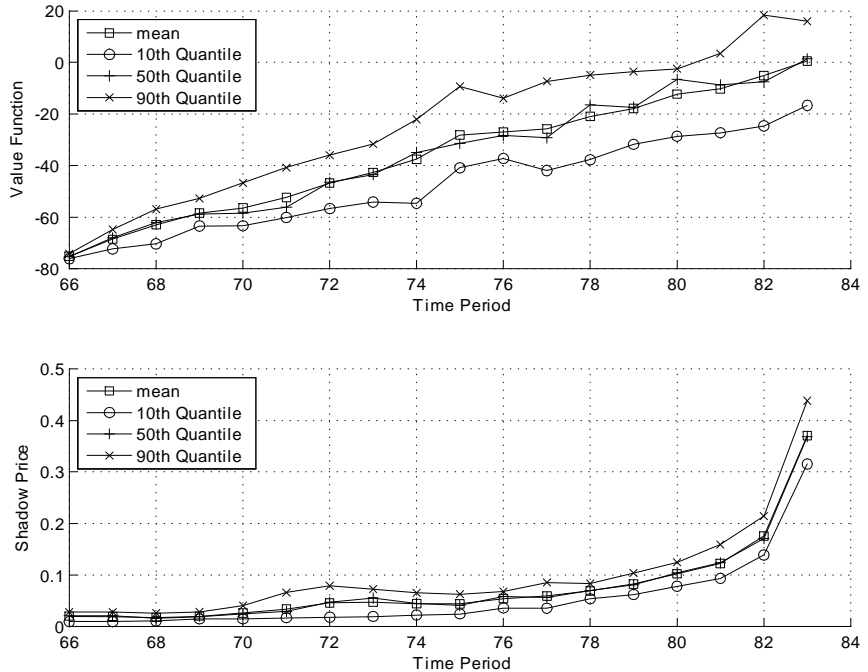
Figure 15

Wealth, housing and consumption: 1900 Cohort, High Education
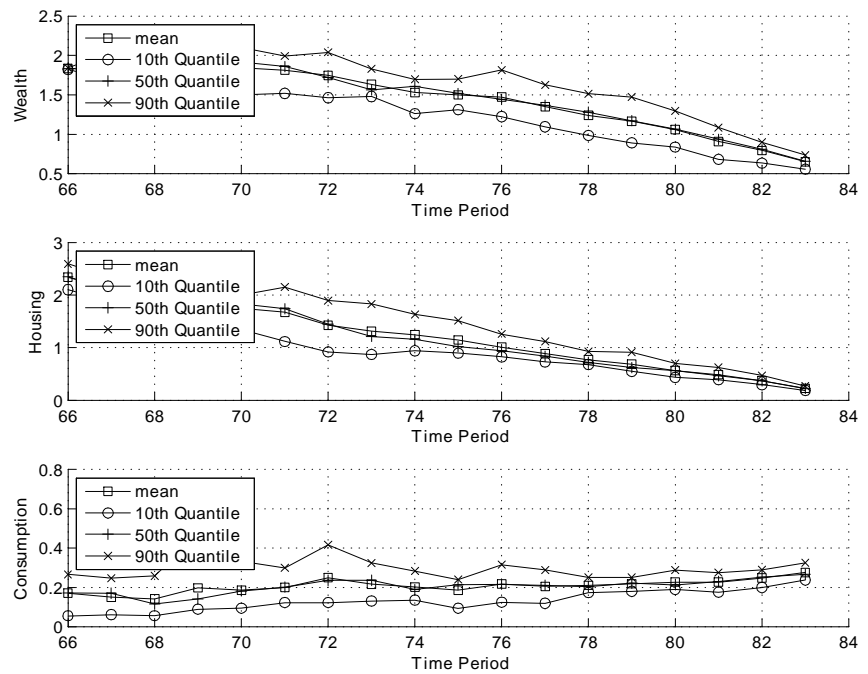

Figure 16

Utility and the shadow price: 1900 Cohort, High Education
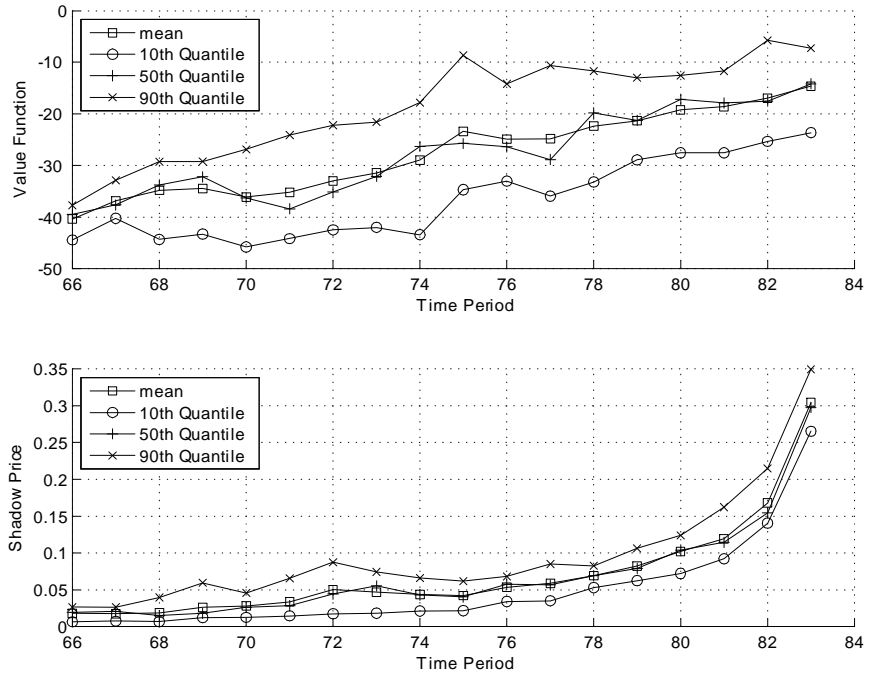
Figure 17

Wealth, housing and consumption: 1910 Cohort, Low Education
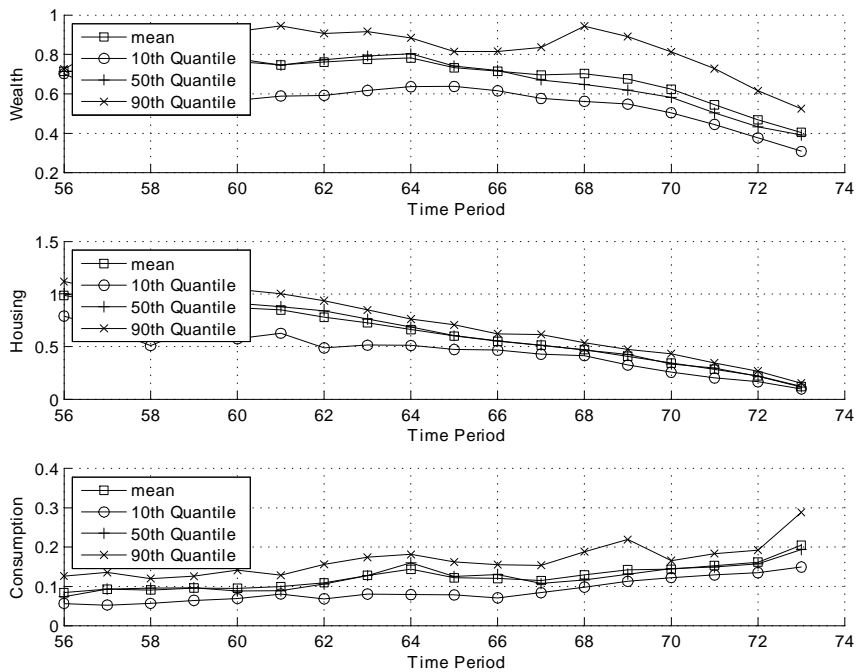

Figure 18

Utility and the shadow price: 1910 Cohort, Low Education
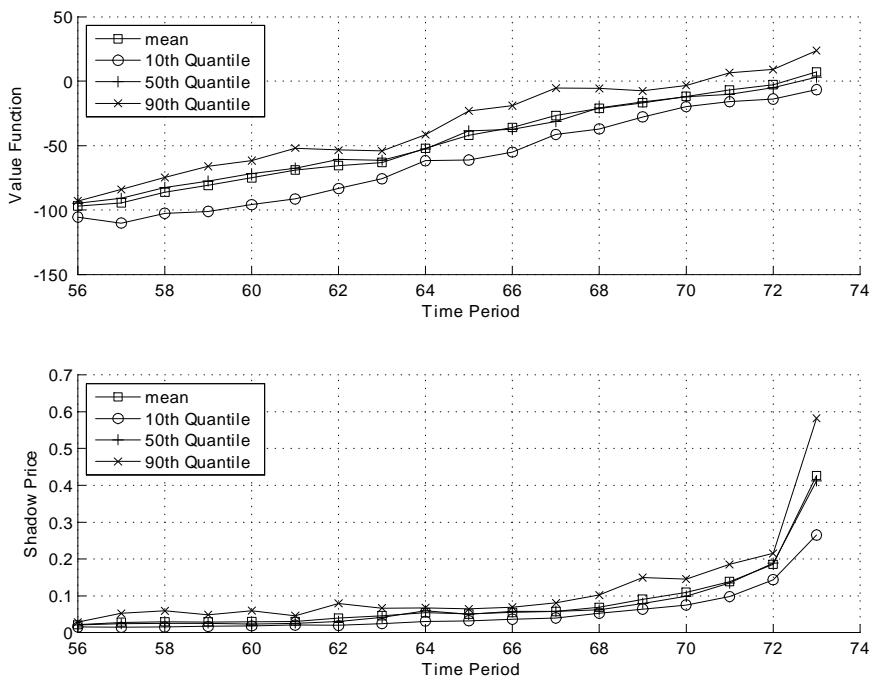
Figure 19

Wealth, housing and consumption: 1910 Cohort, High Education
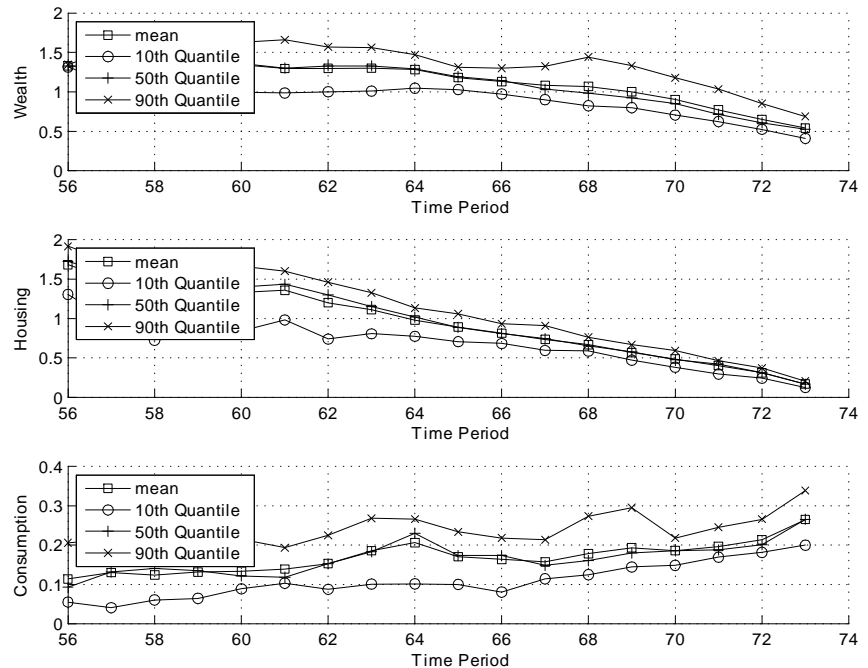

Figure 20

Utility and the shadow price: 1910 Cohort, High Education
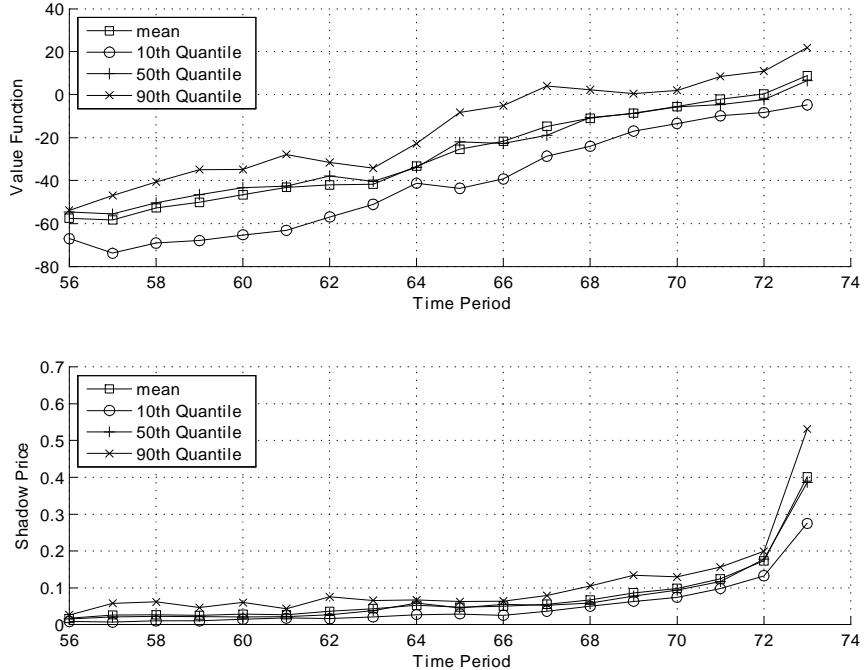
Figure 21

Wealth, housing and consumption: 1920 Cohort, Low Education
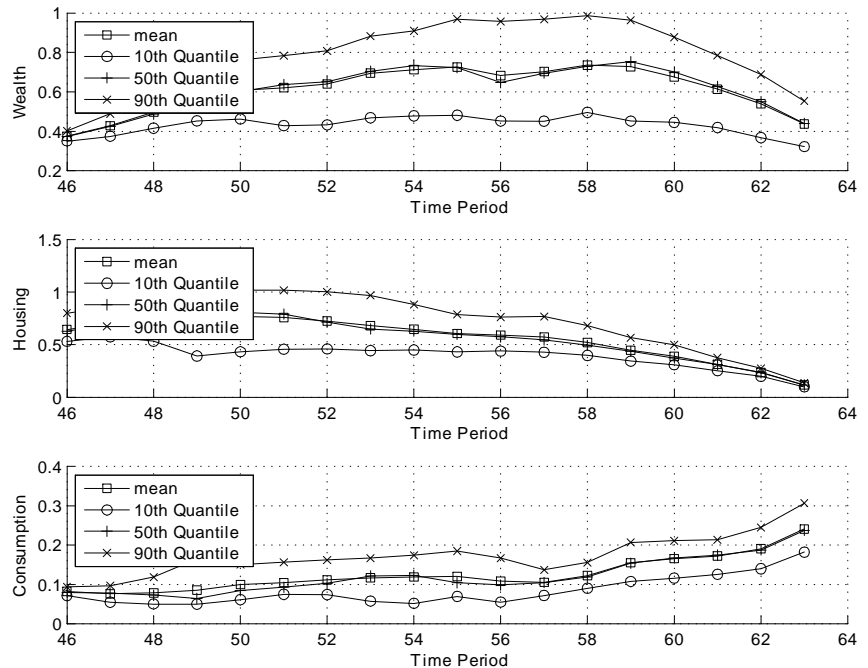

Figure 22

Utility and the shadow price: 1920 Cohort, Low Education
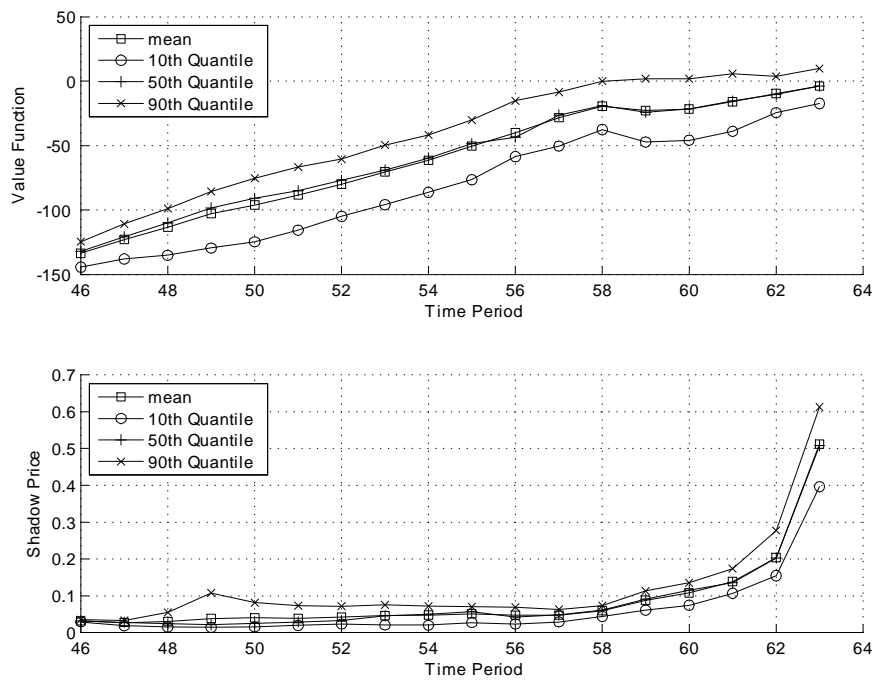
Figure 23

Wealth, housing and consumption: 1920 Cohort, High Education
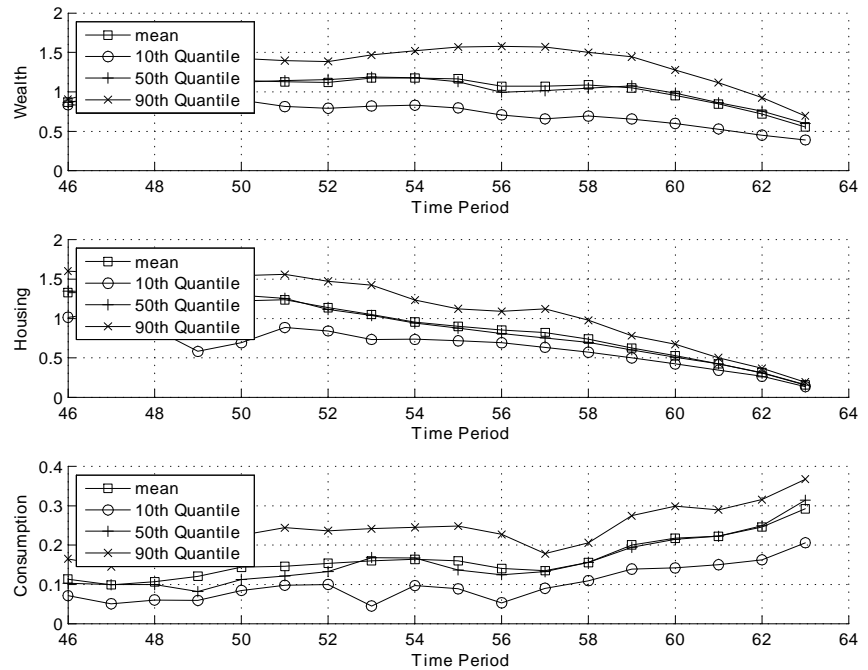

Figure 24

Utility and the shadow price: 1920 Cohort, High Education
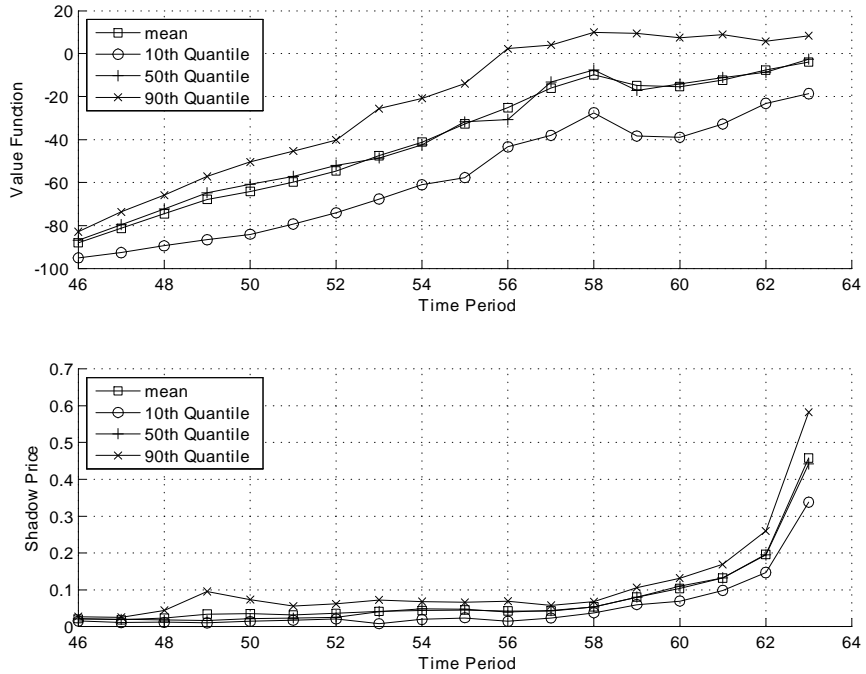
Figure 25

Wealth, housing and consumption: 1930 Cohort, Low Education
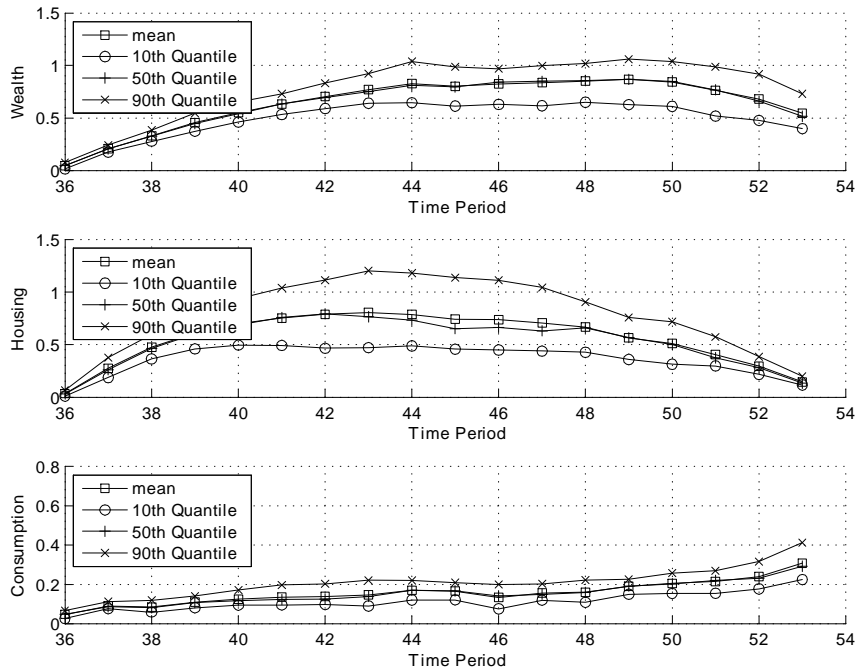

Figure 26

Utility and the shadow price: 1930 Cohort, Low Education
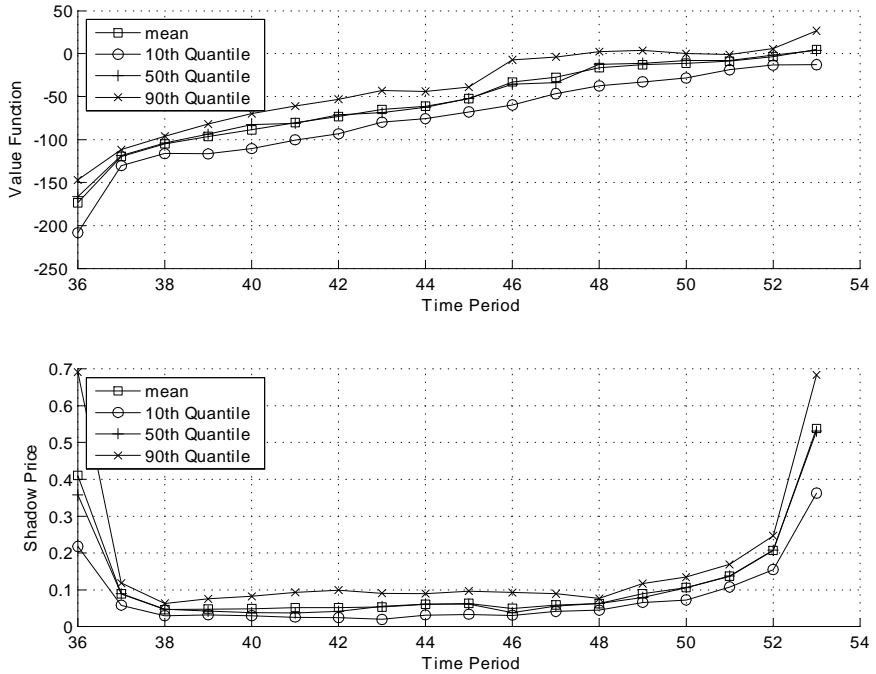
Figure 27

Wealth, housing and consumption: 1930 Cohort, High Education
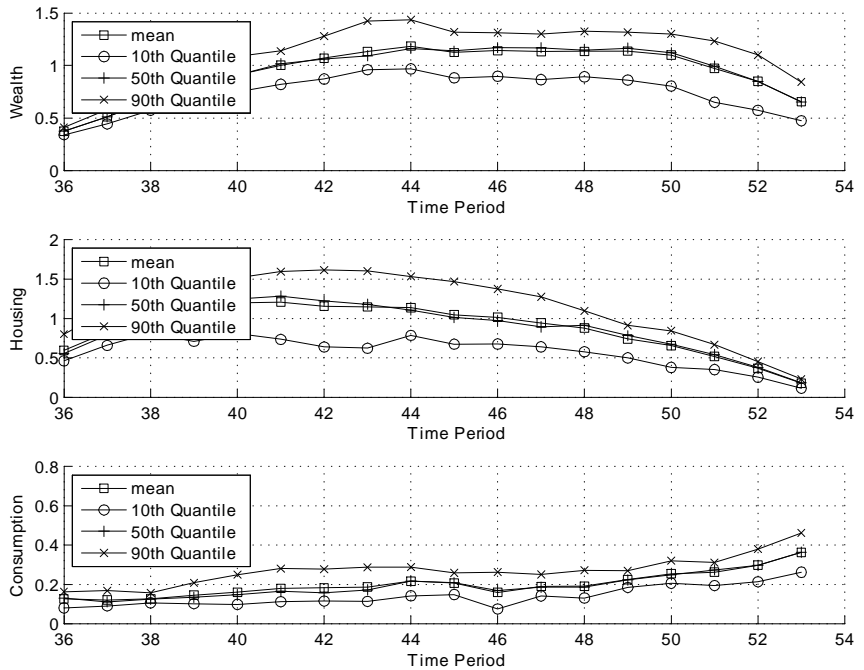

Figure 28

Utility and the shadow price: 1930 Cohort, High Education
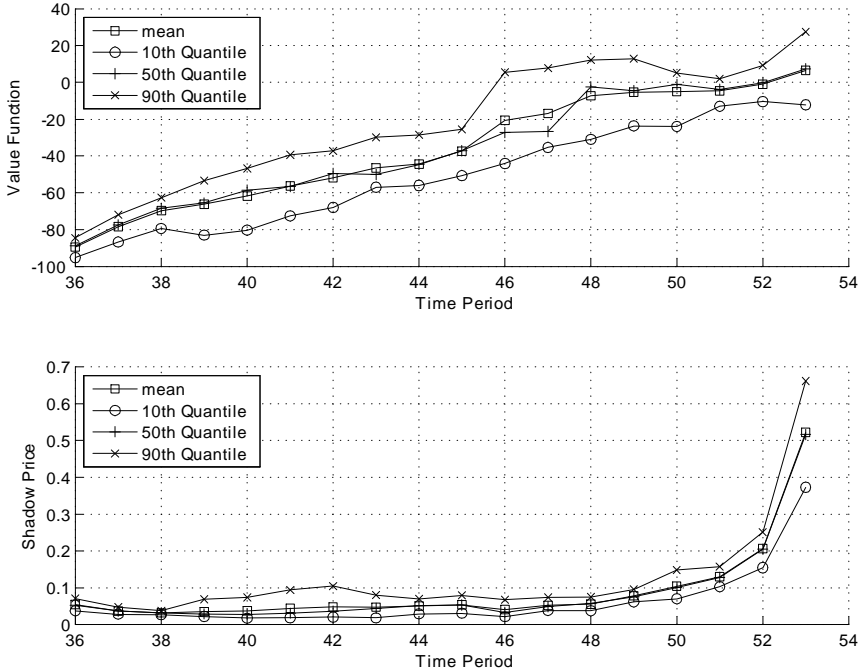
Figure 29

Wealth, housing and consumption: 1940 Cohort, Low Education
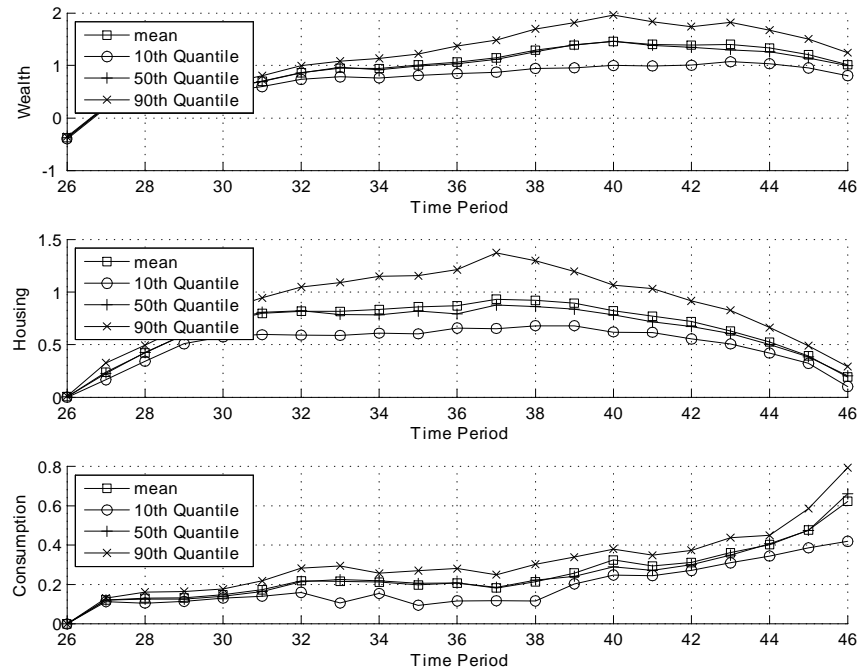

Figure 30

Utility and the shadow price: 1940 Cohort, Low Education
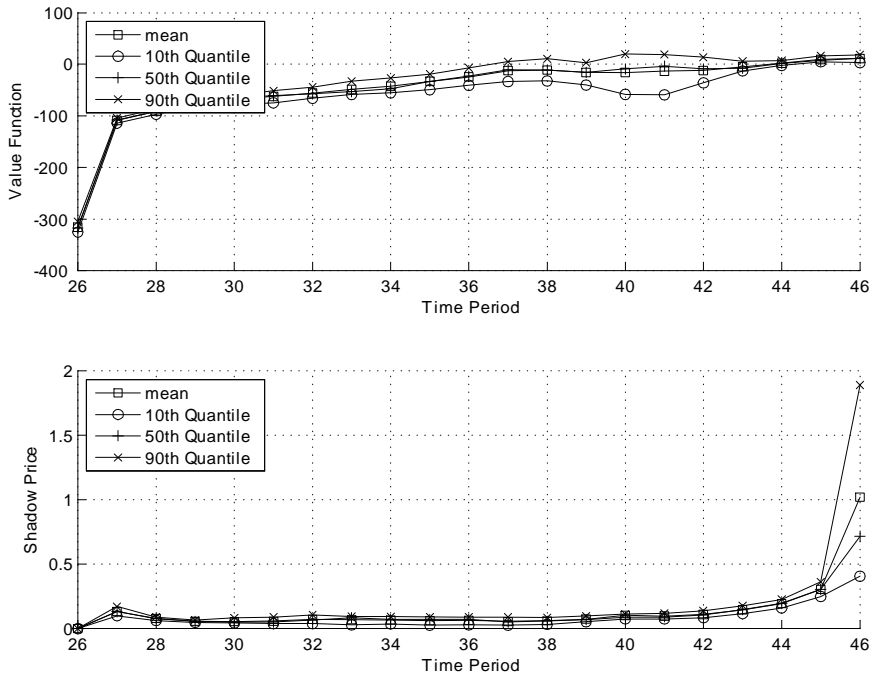
Figure 31

Wealth, housing and consumption: 1940 Cohort, High Education
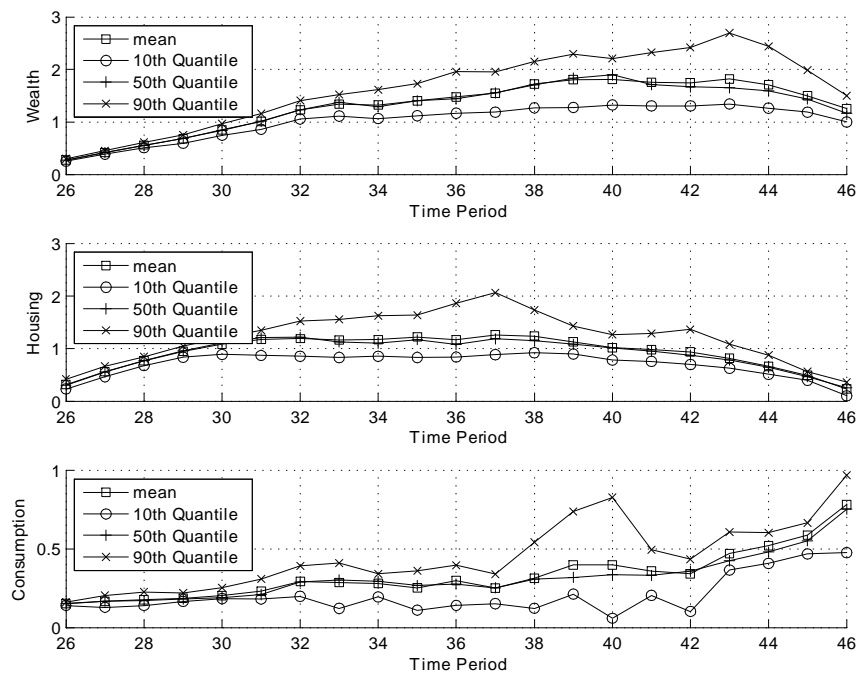

Figure 32

Utility and the shadow price: 1940 Cohort, High Education
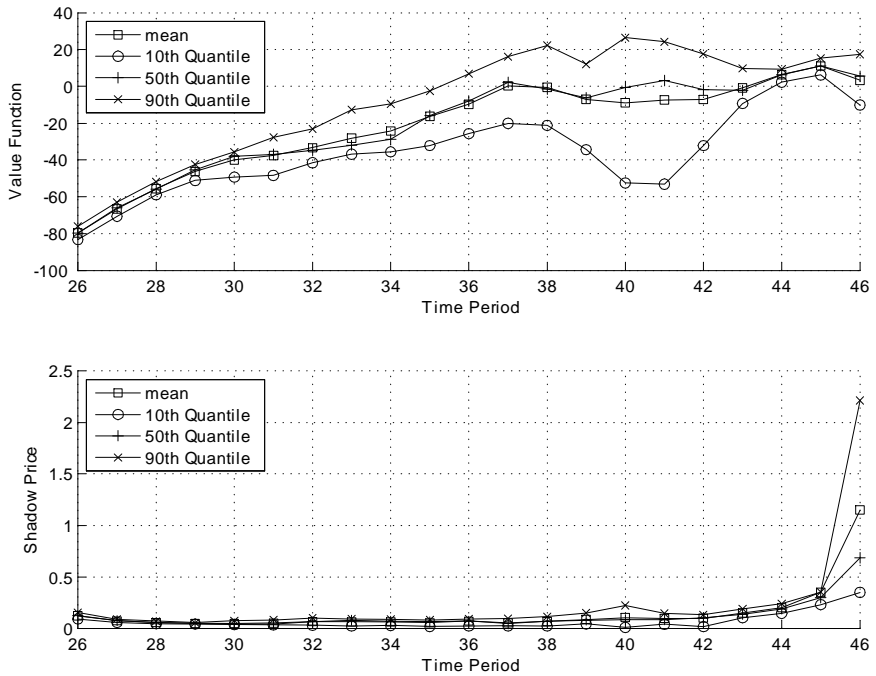
Figure 33

Wealth, housing and consumption: 1950 Cohort, Low Education
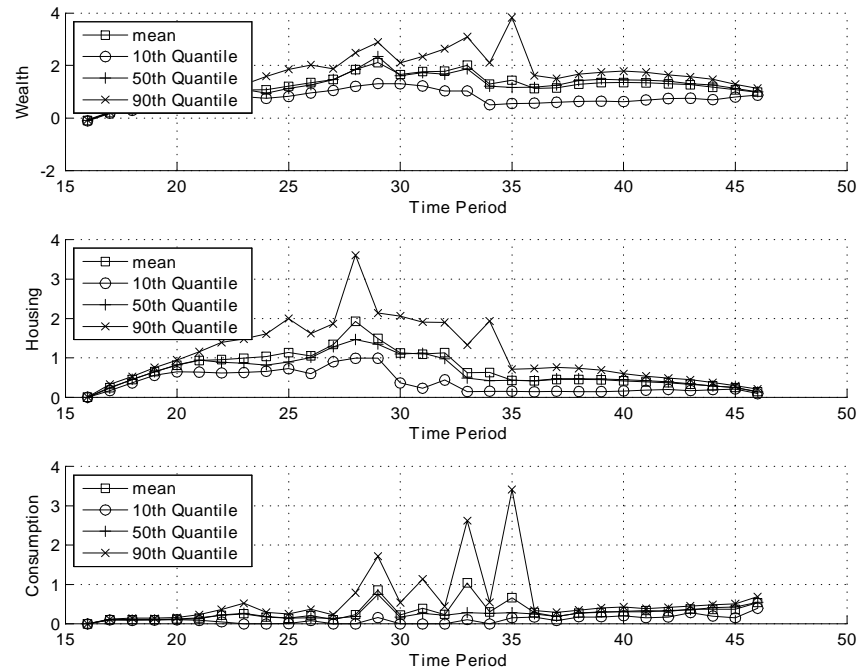

Figure 34

Utility and the shadow price: 1950 Cohort, Low Education
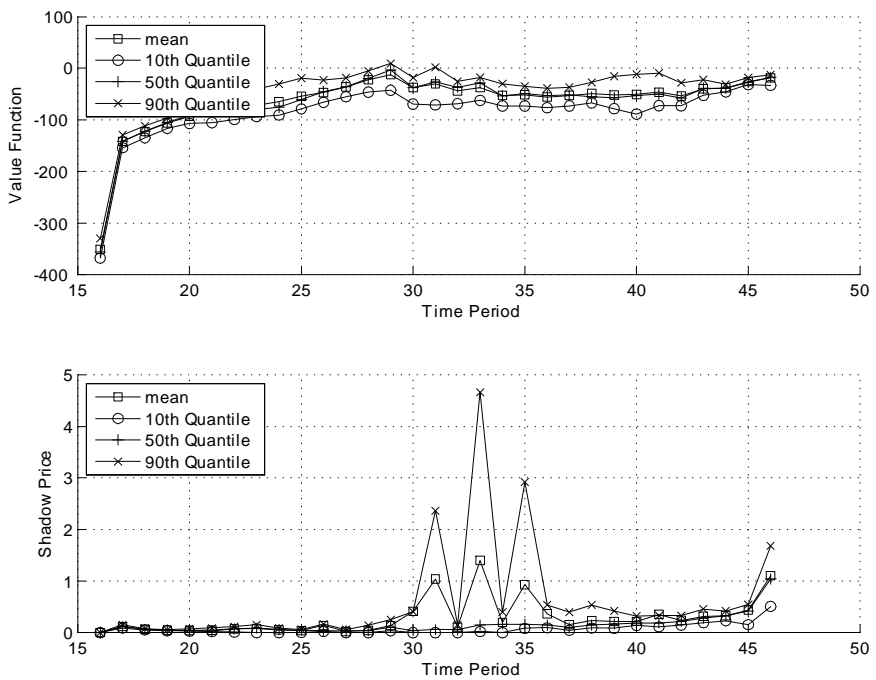
Figure 35

Wealth, housing and consumption: 1950 Cohort, High Education
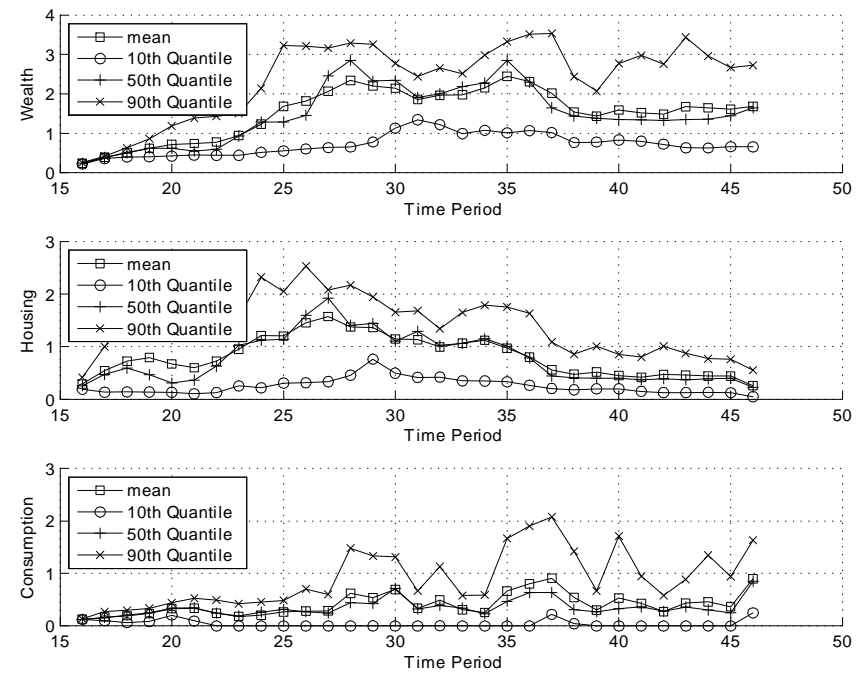

Figure 36

Utility and the shadow price: 1950 Cohort, High Education
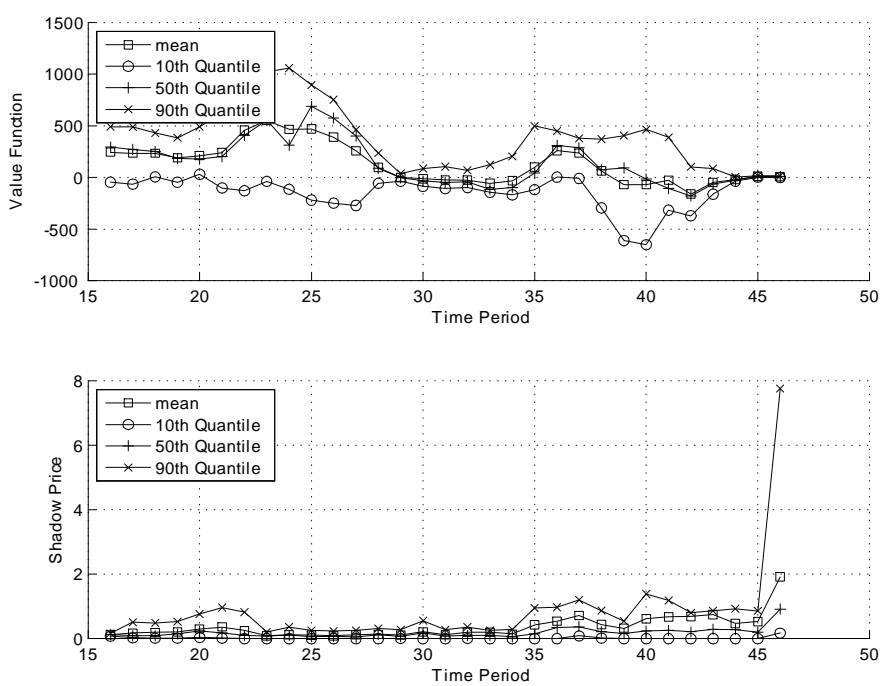
Figure 37

Wealth, housing and consumption: 1960 Cohort, Low Education
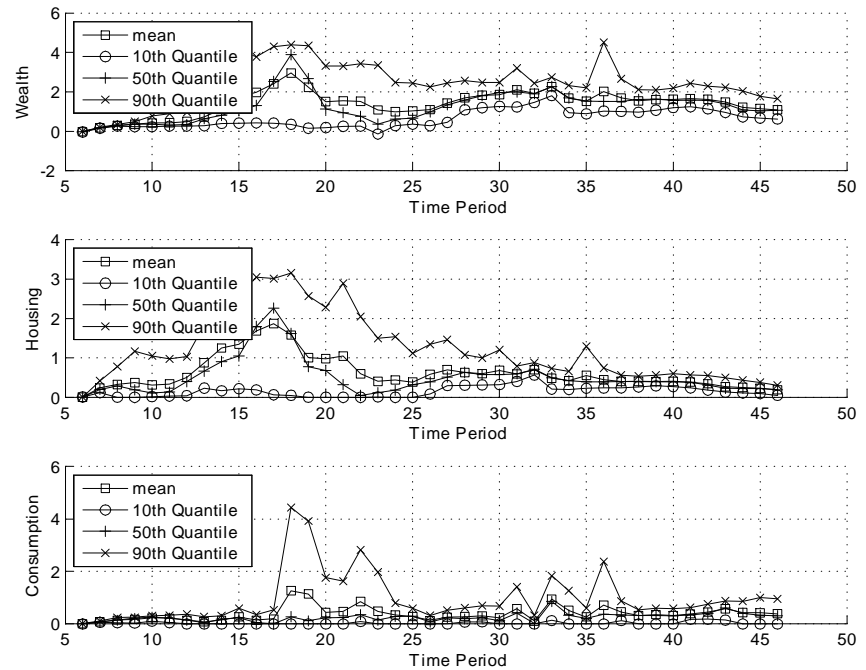

Figure 38

Utility and the shadow price: 1960 Cohort, Low Education
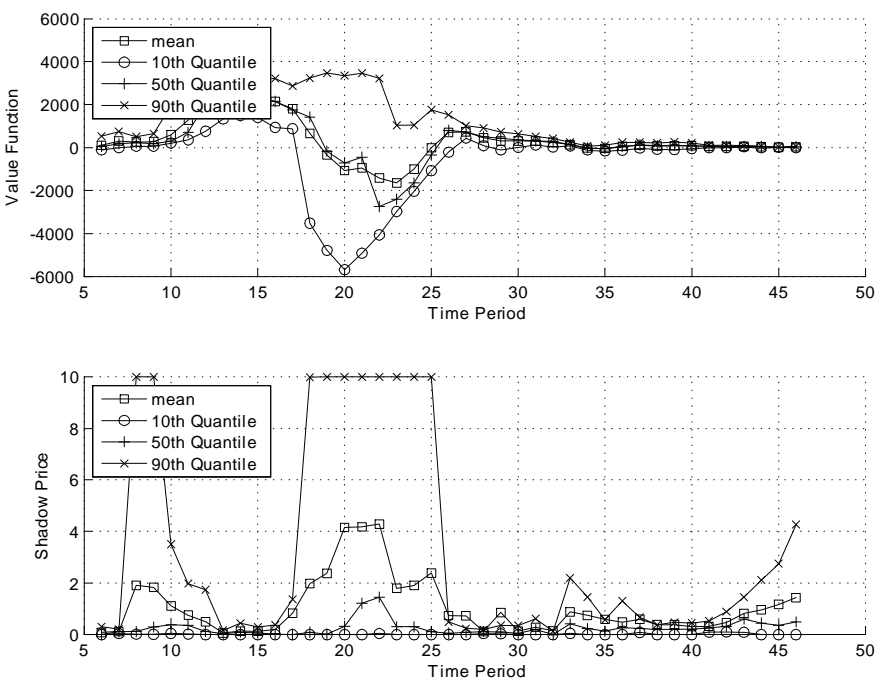
Figure 39

Wealth, housing and consumption: 1960 Cohort, High Education
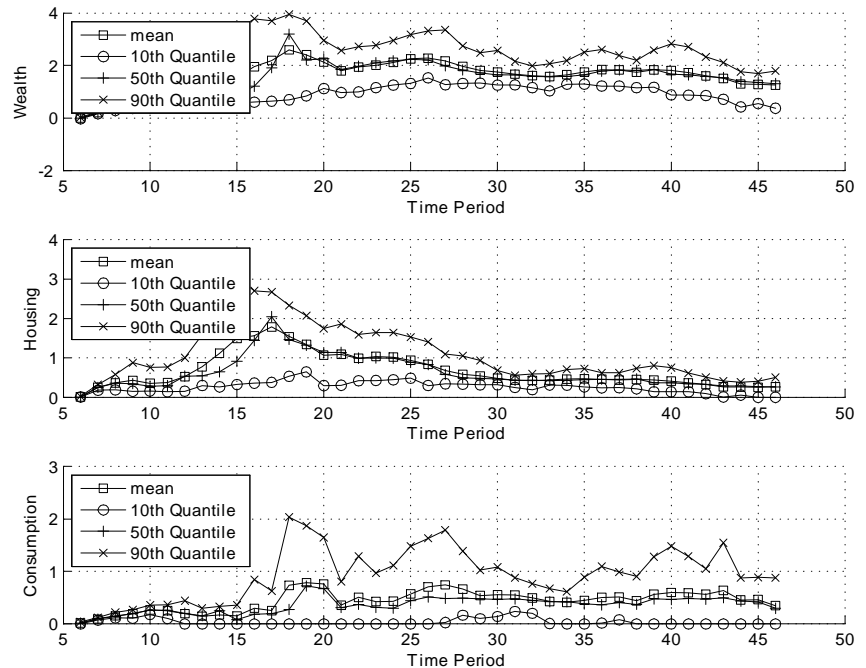

Figure 40

Utility and the shadow price: 1960 Cohort, High Education
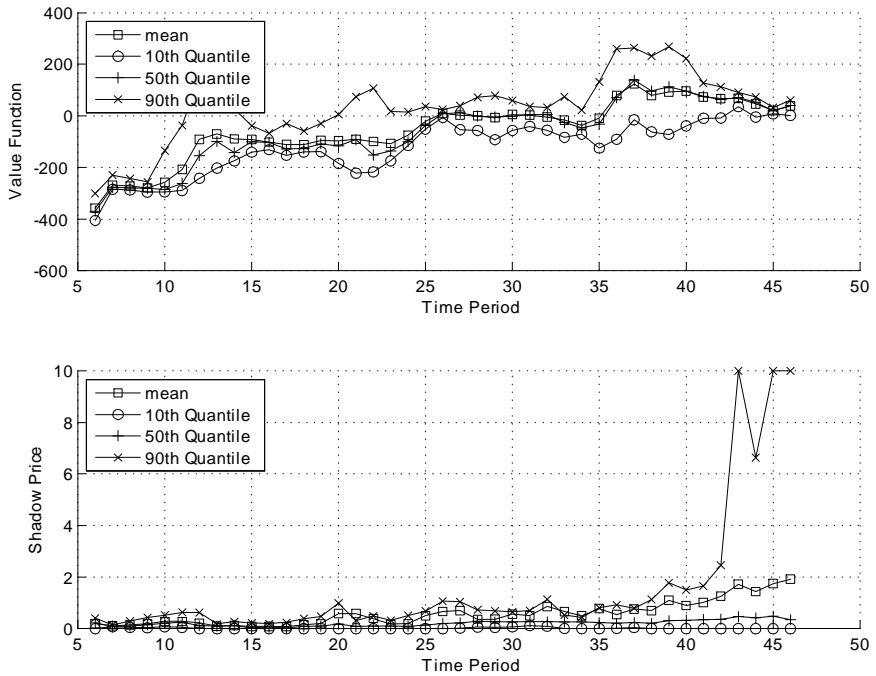
Figure 41

Wealth, housing and consumption: 1970 Cohort, Low Education
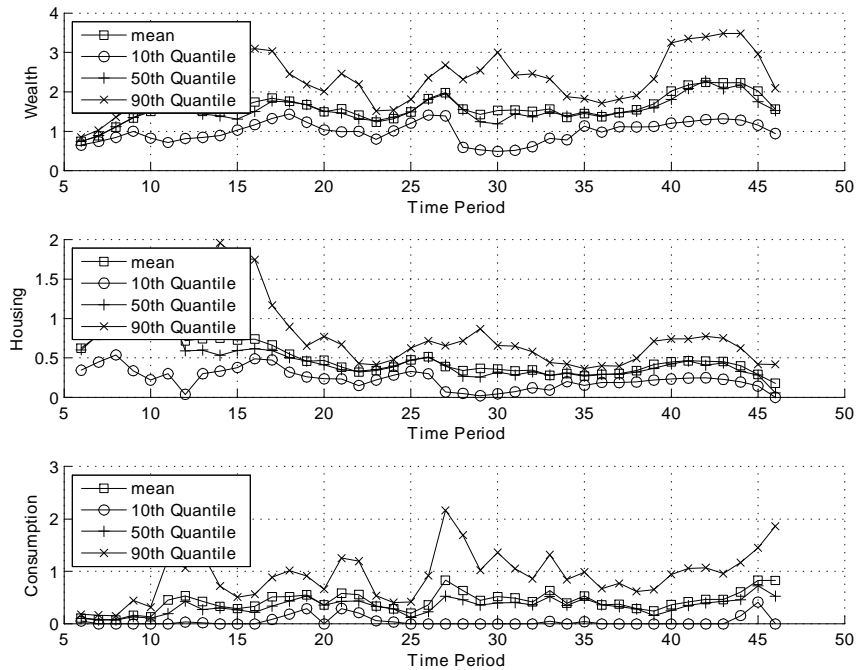

Figure 42

Utility and the shadow price: 1970 Cohort, Low Education
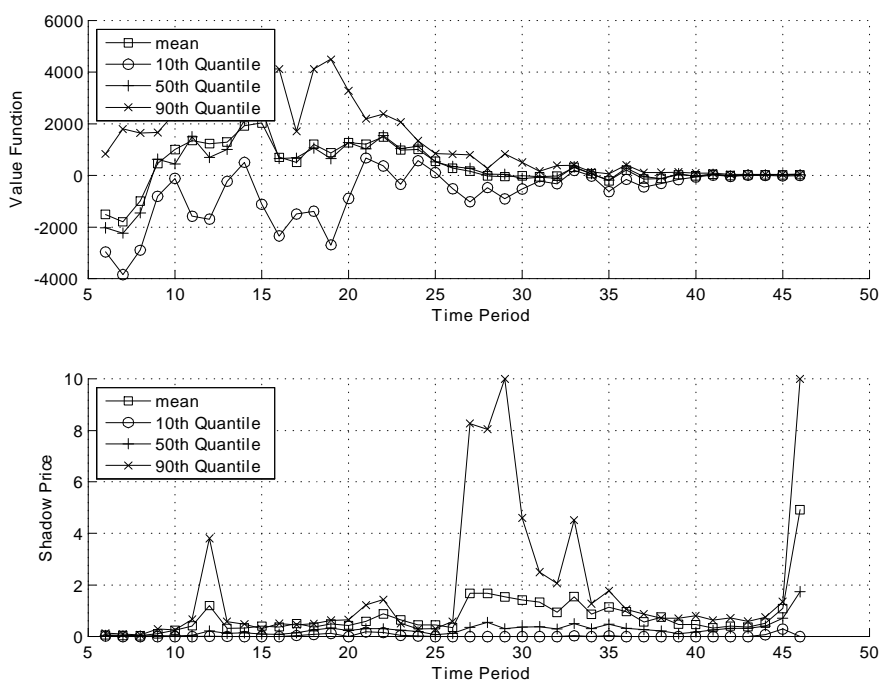
Figure 43

Wealth, housing and consumption: 1970 Cohort, High Education
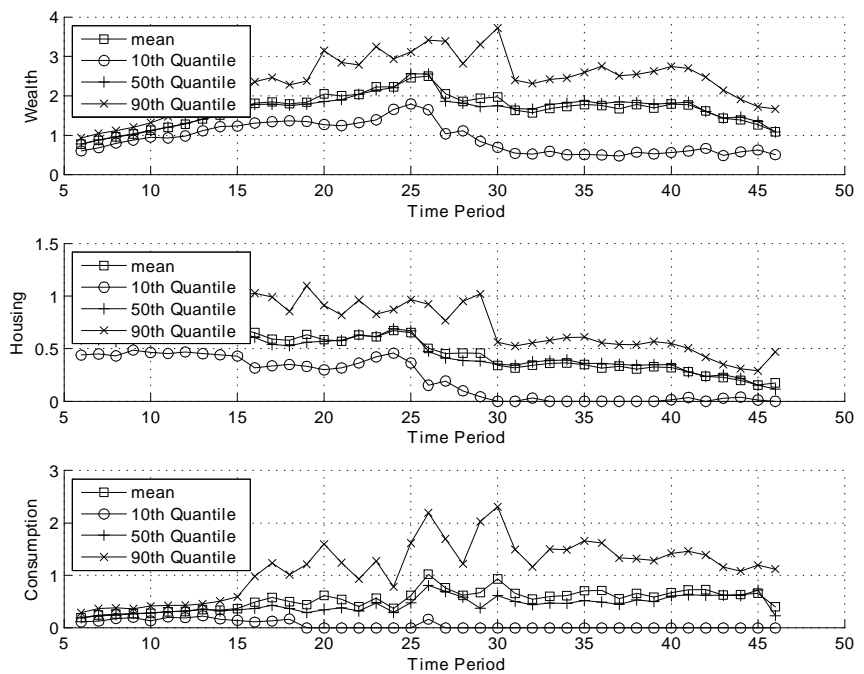

Figure 44

Utility and the shadow price: 1970 Cohort, High Education
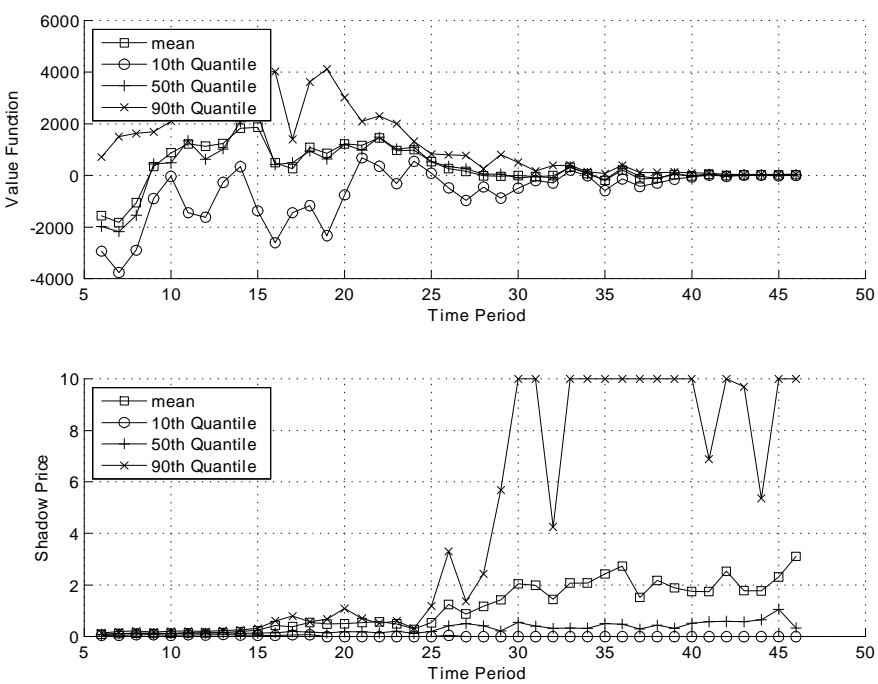
Figure 45

Wealth, housing and consumption: 1940 Cohort, High Education, Low Growth in House Prices
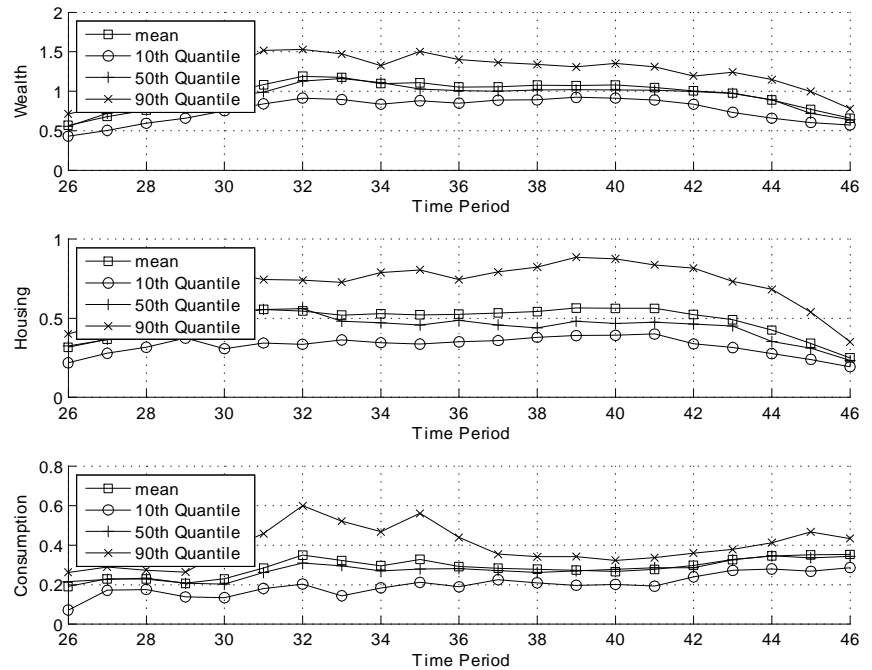

Figure 46

Utility and shadow price: 1940 Cohort, High Education, Low Growth in House Prices
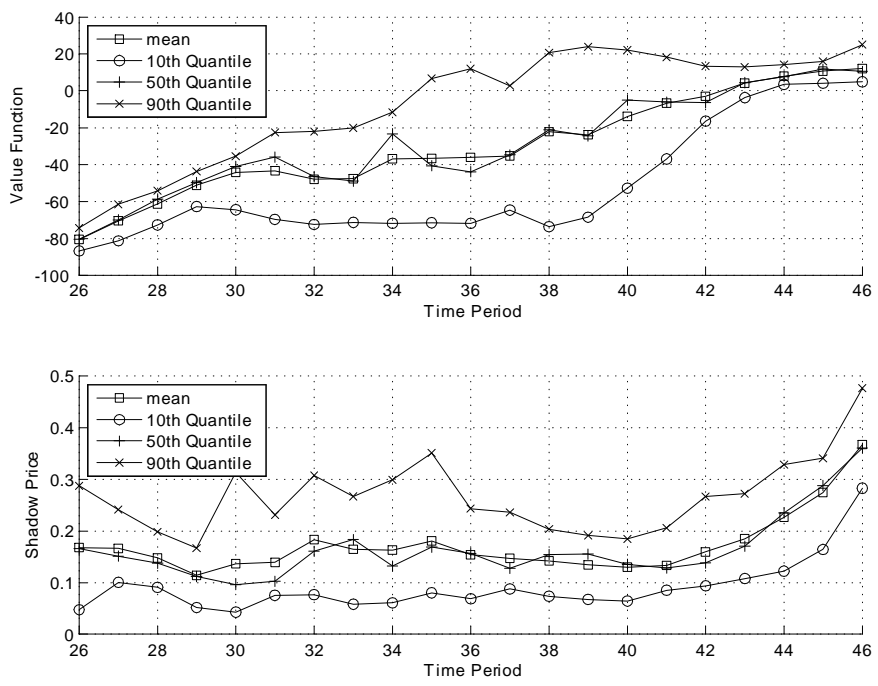
Figure 47

Wealth, housing and consumption: 1940 Cohort, High Education,

Loose Constraints
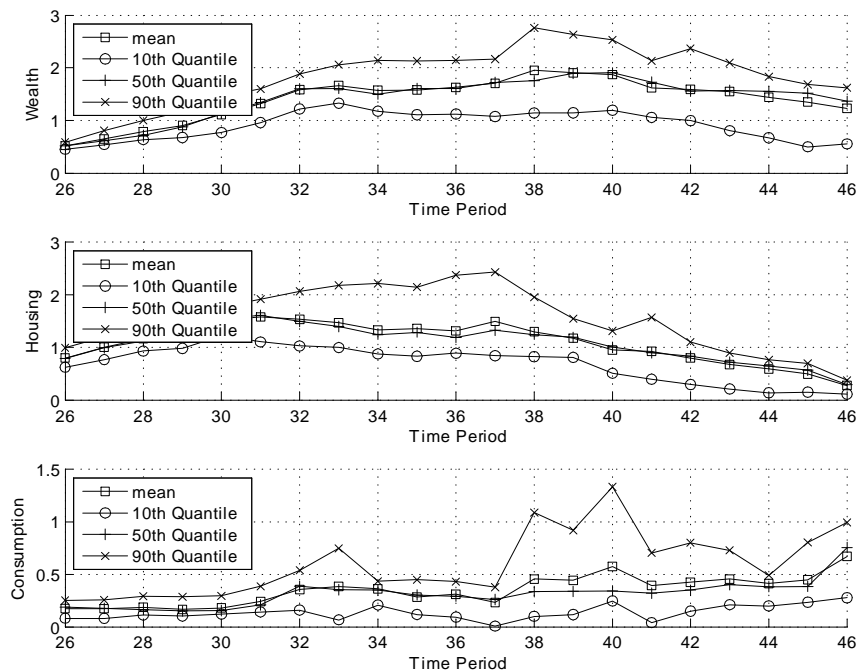

Figure 48

Utility and Shadow Price: 1940 Cohort, High Education, Loose Constraints
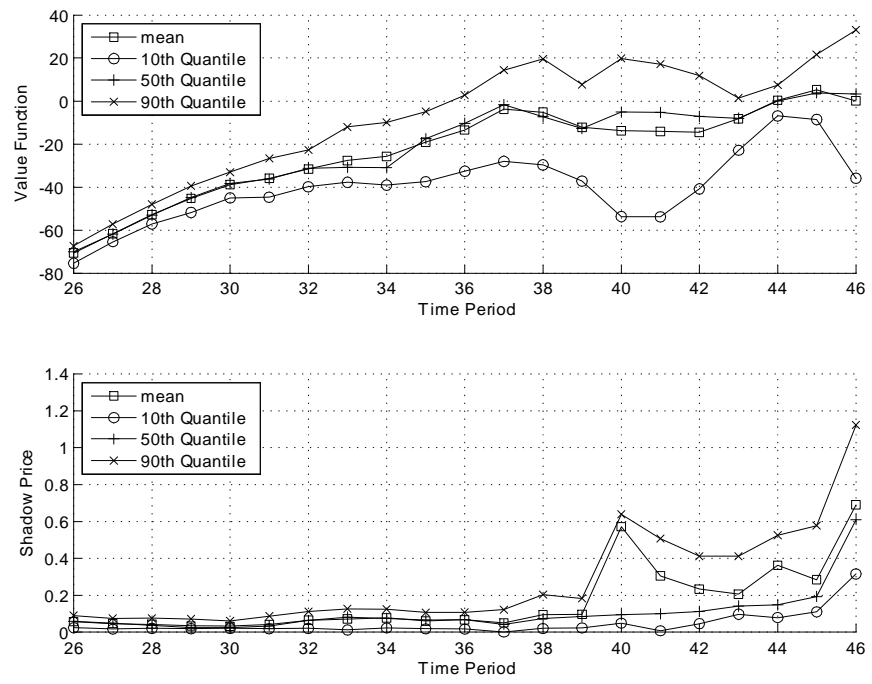
Figure 49

Wealth, housing and consumption: 1940 Cohort, High Education, Tight Constraints
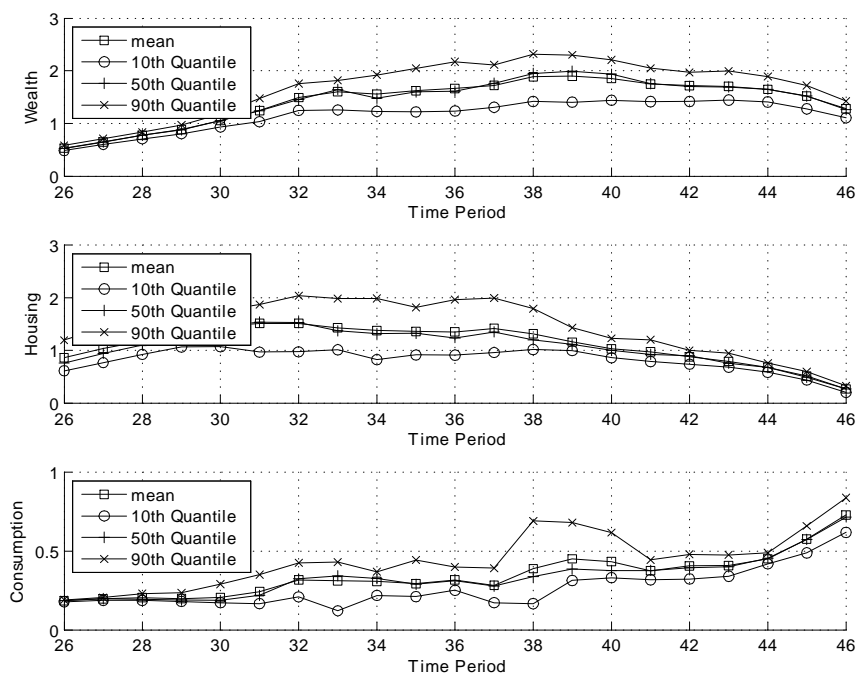

Figure 50

Utility and Shadow Price: 1940 Cohort, High Education, Tight Constraints
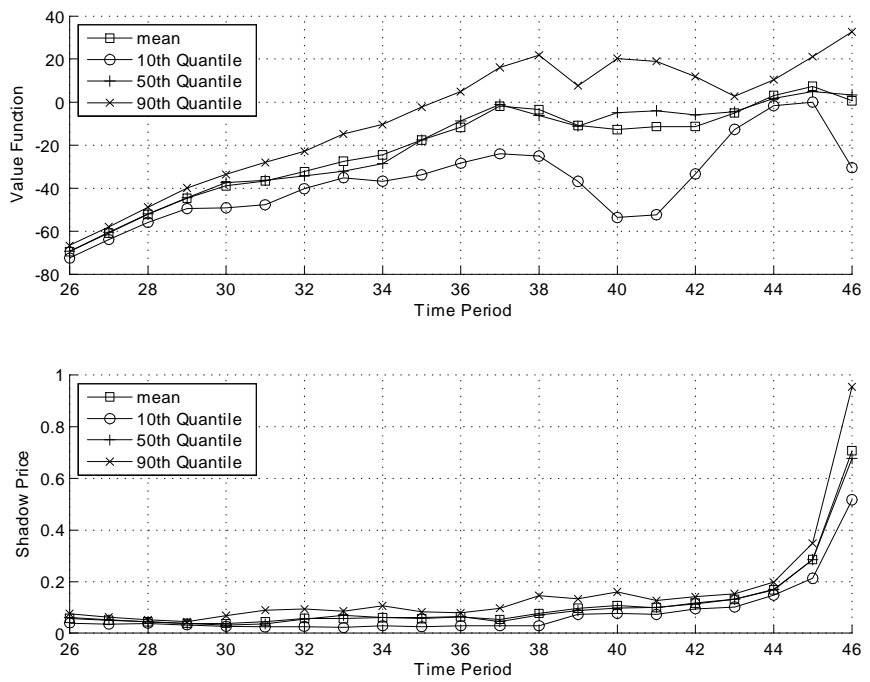